\title{
The structural dynamics of output growth and inflation: some international evidence
}

\author{
Fabio Canova, ICREA-UPF, CREI, AMeN and CEPR * \\ Luca Gambetti, UAB and Universita' di Modena \\ Evi Pappa, UAB and CEPR
}

First version, April 2006

This version August 2006

\begin{abstract}
We examine the dynamics of output growth and inflation in the US, Euro area and UK using a structural time varying coefficient VAR. There are important similarities in structural inflation dynamics across countries; output growth dynamics differ. Swings in the magnitude of inflation and output growth volatilities and persistences are accounted for by a combination of three structural shocks. Changes over time in the structure of the economy are limited and permanent variations largely absent. Changes in the volatilities of structural shocks matter.
\end{abstract}

JEL classification: C11, E12, E32, E62

Key Words: Variability, Persistence, Transmission, Structural time varying VARs.

${ }^{*}$ We would like to thank an anonymous referee, Andrew Scott, Thomas Lubik and Paolo Surico for comments and suggestions. 


\section{Introduction}

The dynamics of output growth and inflation have been the focus of intense research over the last 35 years and the question of what causes fluctuations in these two variables is still unsettled. Recently, the literature has turned to documenting the time profile of the dynamics of these two variables. For example, Blanchard and Simon (2000), McConnell and Perez Quiroz (2001), Sargent and Cogley (2001) and Stock and Watson (2003) report a decline in the volatility of real activity and inflation in the US and a reduction in the persistence of inflation since the early 1980s; Benati (2004) detects significant shifts in the volatility and the persistence of UK inflation; Batini (2002), Gadzinski and Orlandi (2004), O'Really and Whelan (2004) find visual evidence of changes but little support for a once-and-for-all break in the time profile of inflation dynamics in the Euro area.

What are the reasons for these changes? Two possibilities are often suggested. First, that the mechanism through which exogenous disturbances spread to the economy and propagate over time has changed as a result of alterations in the preferences of consumers and/or policymakers, or the objective function of firms. Second, that the shocks that perturb the economy have changed magnitude and frequency over time. Changes in policymakers' preferences have been discussed at length. For example, Clarida, Gali and Gertler (2000), Cogley and Sargent (2001) and (2005) and Lubik and Schorfheide (2004) have argued that monetary policy was "loose" in fighting inflation in the 1970s but became more aggressive since the early 1980s. Leeper and Zha (2003), Sims and Zha (2006), Canova and Gambetti (2004), Primiceri (2005) and others are critical of this view since they estimate stable policy rules and find the transmission of policy shocks roughly unchanged over time.

While it is often stressed that inflation is a monetary phenomena and popular sticky price New-Keynesian models give a powerful role to monetary policy - stabilizing output implies inflation stabilization, policy shocks are only a minor source of variation in real activity and other shocks account for a large percentage of inflation fluctuations at business cycle frequencies. For example, productivity disturbances, either of neutral, or of investment specific type, have been found to be important in generating real cyclical fluctuations. Given that the increase in productivity of the 1990s was, to a large extent, unexpected (see e.g. Gordon (2004)), one may conceive that changes in the dynamics of productivity disturbances may account for the time variations observed, not only in the period, but also in the whole sample. Similarly, the way fiscal policy was conducted in the late 1970s and the early 1980s differed considerably from the way it was conducted in the 1990s. Hence, fiscal policy could also potentially explain changes in the dynamics of output and inflation. Gambetti, et. al. 
(2005) find that, indeed, a portion of the observed variations in the dynamics of US output and inflation is due to changes in the way technological and fiscal disturbances spread to the economy and to a decline in their volatility.

This evidence is suggestive about the nature of the changes but it leaves the question of whether idiosyncratic or global factors are behind the observed variations open. There are reasons to believe that both arguments could be valid. In the last 35 years, the US economy has witnessed a number of specific changes, which go from alterations in the management of inventories and production (see McConnell and Perez Quiroz (2001)), to financial market deregulation (see Blanchard and Simon (2001)), to sectorial and labour market changes. On the other hand, the shocks hitting the US economy have also become more global in nature. Hence, an international perspective may help to evaluate not only whether changes in the dynamics are common across countries but also whether common explanations can be found and, therefore, help designing policies which effectively deal with these changes and flexibly adapt to an evolving macroeconomic environment.

This paper investigates the nature and the causes of the structural changes in the dynamics of output growth and inflation in the US, the UK and the Euro area. While some structural evidence exists for the US and the UK (see e.g. Gambetti et. al. (2005), and Benati and Mumtaz (forthcoming)), only reduced form, time series and micro based evidence on the dynamics of inflation exist for the Euro area. We therefore contribute to the literature in two distinct ways; we jointly examine output growth and inflation dynamics from a structural point of view; and we compare sources of structural variations across countries.

Since many interesting issues could be addressed, we gear our investigation to answer three main questions. First, are there structural changes in the volatility and the persistence of output growth and inflation? Are they comparable in size and timing across countries? Second, what are the reasons for these changes? Do they reflect time variations in the transmission or in the size and the nature of structural shocks? Third, are there common sources of variations across countries?

To address these questions we employ time varying coefficients VAR models, where coefficients evolve according to a nonlinear transition equation and use Markov Chain Monte Carlo methods to estimate the posterior distribution of the quantities of interest.

We identify three types of structural shocks (roughly, technology, real demand and monetary disturbances) using robust sign restrictions. These restrictions naturally arise in a large class of dynamic stochastic general equilibrium (DSGE) models; they are uncontroversial, since they are common to both RBC style and New-Keynesian style models and 
robust, in the sense they hold regardless of the parameterisation and of the nature of the policy rules (see e.g. Gambetti et. al. (2005)). Since the systems we examine are of small scale, and therefore potentially subject to specification and interpretation problems, we also study whether the shocks we recover proxy for other sources of structural disturbances, for example, oil shocks, or omitted variables, such as inflation expectations, both of which are typically thought to matter for the dynamics of output growth and inflation.

The results of our investigation can be summarized as follows. We show that there are important similarities in the structural dynamics of inflation across countries over the last 35 years. However, structural output growth dynamics acquired significant cross country similarities only since the early 1990s. Swings in the magnitude of volatilities and persistence are typically accounted for by a combination of all three structural shocks. We document that sources of inflation persistence and volatility are similar but that sources of output growth dynamics vary across countries. Within a country, sources of output growth and inflation variations are different.

Time variations in the structure of the three economies appear to have been limited in time and scope and permanent shifts, in one direction or another, are largely absent. The 1970s in the US and the UK and the 1990s in the US are notable exceptions. Changes in the volatilities of structural shocks are as least as important as changes in the structure to account for the evidence. In general, it is impossible to explain the Great Inflation of the 1970s and the substantive output growth of the 1990s with one single explanation. In the US changes in the transmission and in the variability of demand shocks appear to be important; in the Euro area changes in the transmission and the volatility of monetary policy shocks and in the volatility of supply shocks matter; in the UK changes in the transmission of demand shocks and in the volatility of supply and monetary policy shocks account for the observed output growth and inflation dynamics.

The rest of the paper is organized as follows. The next section describes the empirical framework used in the analysis. Section 3 deals with estimation issues and section 4 discusses the identification restrictions. Section 5 presents the results and section 6 concludes.

\section{The empirical model}

Let $y_{t}$ be a $4 \times 1$ vector of time series including real output growth, the inflation rate, a short term nominal rate and the growth rate of money with the representation

$$
y_{t}=A_{0, t}+\sum_{j=1}^{p} A_{j, t} y_{t-j}+\varepsilon_{t}
$$


where $A_{0, t}$ is a $4 \times 1$ vector; $A_{j, t}$, are $4 \times 4$ matrices, for each $j$ and $\varepsilon_{t}$ is a $4 \times 1$ Gaussian white noise with zero mean and covariance $\Sigma$. Letting $A_{t}=\left[A_{0, t}, A_{1, t}, A_{2, t} \ldots A_{p, t}\right], x_{t}^{\prime}=$ $\left[1_{4}, y_{t-1}^{\prime} \ldots y_{t-p}^{\prime}\right]$, where $1_{4}$ is a row vector of ones of length 4 , using $\operatorname{vec}(\cdot)$ to denote the stacking column operator and setting $\theta_{t}=\operatorname{vec}\left(A_{t}^{\prime}\right)$, we rewrite $(1)$ as

$$
y_{t}=X_{t}^{\prime} \theta_{t}+\varepsilon_{t}
$$

where $X_{t}^{\prime}=\left(I_{4} \otimes x_{t}^{\prime}\right)$ is a $4 \times 4(4 p+1)$ matrix, $I_{4}$ is a $4 \times 4$ identity matrix, and $\theta_{t}$ is a $4(4 p+1) \times 1$ vector. We assume that $\theta_{t}$ evolves according to

$$
p\left(\theta_{t} \mid \theta_{t-1}, \Omega\right) \propto \mathcal{I}\left(\theta_{t}\right) f\left(\theta_{t} \mid \theta_{t-1}, \Omega\right)
$$

where $\mathcal{I}\left(\theta_{t}\right)$ discards explosive paths of $y_{t}$ and $f\left(\theta_{t} \mid \theta_{t-1}, \Omega\right)$ is parametrized as

$$
\theta_{t}=\theta_{t-1}+u_{t}
$$

where $u_{t}$ is a $4(4 p+1) \times 1$ Gaussian white noise with zero mean, diagonal covariance $\Omega$, uncorrelated with $\varepsilon_{t}$. We discard explosive paths for $\theta_{t}$ as they would imply time series which, with probability one, are at odds with the data we consider.

Note that our specification implies that the forecast errors of the model are non-normal and heteroschedastic. In fact, substituting (4) into (2) we have that $y_{t}=X_{t}^{\prime} \theta_{t-1}+v_{t}$, where $v_{t}=\varepsilon_{t}+X_{t}^{\prime} u_{t}$. We find such a structure appealing since whatever generates coefficient variations also imparts heteroschedastic movements to the variance of the forecasts errors. Sims and Zha (2006) and Cogley and Sargent (2005) have used different specifications for their VARs: the former assume that the variance of $\varepsilon_{t}$ is a function of a Markov switching indicator, while the latter allow for stochastic volatility in the variance of $\varepsilon_{t}$. Our specification do not explicitly model time variations in the variance of $\varepsilon_{t}$. However, our recursive estimation approach non-parametrically allows $\Sigma$ to change over time. Hence, our procedure will not underestimate the extent of time variations in the volatility in any meaningful sense.

Let $S$ be a square root of $\Sigma$, i.e., $\Sigma=S D S^{\prime}$, where $D$ is a diagonal matrix; let $H_{t}$ be an orthonormal matrix, independent of $\varepsilon_{t}$, such that $H_{t} H_{t}^{\prime}=I$ and set $J_{t}^{-1}=H_{t}^{\prime} S^{-1}$. $J_{t}$ is a particular decomposition of $\Sigma$ which transforms (2) in two ways: it produces uncorrelated innovations (via the matrix $S$ ) and it gives a structural interpretation to the equations of the system (via the matrix $H_{t}$ ). Premultiplying $y_{t}$ by $J_{t}^{-1}$ we obtain

$$
J_{t}^{-1} y_{t}=J_{t}^{-1} A_{0, t}+\sum_{j} J_{t}^{-1} A_{j, t} y_{t-j}+e_{t}
$$


where $e_{t}=J_{t}^{-1} \varepsilon_{t}$ satisfies: $E\left(e_{t}\right)=0, E\left(e_{t} e_{t}^{\prime}\right)=H_{t} D H_{t}^{\prime}$. Equation (5) represents the class of "structural" representations of interest: for example, a Choleski system is obtained choosing $S$ to be lower triangular matrix and $H_{t}=I_{4}$, and more general patterns, with non-recursive zero restrictions, result choosing $S$ to be non-triangular and $H_{t}=I_{4}$.

In this paper, $S$ is an arbitrary square root matrix. Hence, identifying structural shocks is equivalent to choosing $H_{t}$. We select $H_{t}$ so that responses at $t+k, k=1,2, \ldots, K_{1}$, satisfy certain sign restrictions. We prefer to identify structural shocks via sign restrictions for three reasons. First, the contemporaneous zero restrictions conventionally used are often absent from those models one uses to interpret the results. Second, standard decompositions underidentify structural shocks whenever the economy is on an indeterminate path (see Lubik and Schorfheide (2004)). Third, sign restrictions do allow for time variations in the magnitude of the responses to shocks. Clearly, since our identification restrictions are based on inequality constraints, they do not deliver exact identification. A strategy to deal with this multiplicity is outlined below.

Letting $C_{t}=\left[J_{t}^{-1} A_{0 t}, \ldots, J_{t}^{-1} A_{p t}\right]$, and $\gamma_{t}=\operatorname{vec}\left(C_{t}^{\prime}\right)$, (5) can be written as

$$
J_{t}^{-1} y_{t}=X_{t}^{\prime} \gamma_{t}+e_{t}
$$

As in fixed coefficient VARs, there is a mapping between the structural coefficients $\gamma_{t}$ and the reduced form coefficients $\theta_{t}$ since $\gamma_{t}=\left(J_{t}^{-1} \otimes I_{4(p+1)}\right) \theta_{t}$. Whenever $\mathcal{I}\left(\theta_{t}\right)=1$, we have

$$
\gamma_{t}=\left(J_{t}^{-1} \otimes I_{4(p+1)}\right)\left(J_{t-1}^{-1} \otimes I_{4(p+1)}\right)^{-1} \gamma_{t-1}+\eta_{t}
$$

where $\eta_{t}=\left(J_{t}^{-1} \otimes I_{4(p+1)}\right) u_{t}$. Hence, the vector of structural shocks $\xi_{t}^{\prime}=\left[e_{t}^{\prime}, \eta_{t}^{\prime}\right]^{\prime}$ is a white noise process with zero mean and covariance matrix $\left[\begin{array}{cc}H_{t} D H_{t}^{\prime} & 0 \\ 0 & E\left(\left(J_{t}^{-1} \otimes I_{4(p+1)}\right) u_{t} u_{t}^{\prime}\left(J_{t}^{-1} \otimes I_{4(p+1)}\right)^{\prime}\right)\end{array}\right]$. Note that the structural model contains two types of shocks: VAR disturbances, $e_{t}$, and parameters disturbances, $\eta_{t}$. In general, the latter do not have a clear economic interpretation. However, for the equation representing a policy rule, they may capture changes in the preferences of the monetary authority (see e.g. Canova and Gambetti (2004)).

To study the transmission of disturbances one typically employs impulse responses. Impulse responses are generally computed as the difference between two realizations of $y_{i, t+k}$ which are identical up to time $t$, but one assumes that between $t$ and $t+k$ a shock in the j-th component of $e_{t+k}$ occurs only at time $t$, and the other that no shocks take place at all dates between $t$ and $t+k, k=1,2, \ldots$

In a TVC model, responses computed this way disregard the fact that structural coefficients may also change with the horizon $k$. Hence, meaningful response functions ought to measure the effects of a shock in $e_{j t}$ on $y_{i t+k}$, allowing future shocks to the structural 
coefficients to be non-zero. The responses we present are obtained as the difference between two conditional expectations of $y_{i t+k}$. In both cases we condition on the history of the data and of the coefficients, on the structural parameters of the transition equation (which are function of $J_{t}$ ) and all future shocks. However, in one case we condition on a draw for the current shock, while in the other, the current shock is set to zero.

While our responses resemble the impulse response functions suggested by Gallant et al. (1996), Koop et al. (1996) and Koop (1996), two important differences need to be noted. First, our responses are history dependent but state independent - histories are not random variables. Second, while responses to VAR disturbances are independent of the sign and the size of the shocks (as with a fixed coefficient model), the size and the sign of shocks to the coefficients may, in principle, matter for the dynamics of the system. For a shock in the $j$-th structural equation of the VAR, responses computed at $t$ for horizon $k$ are:

$$
\begin{aligned}
& I R_{y}^{j}(t, 1)=J_{t}^{-1, i} e_{j, t} \\
& I R_{y}^{j}(t, k)=\Psi_{t+k, k-1}^{j} e_{j, t} \quad k=2,3, \ldots
\end{aligned}
$$

where $\Psi_{t+k, k-1}=\mathcal{S}_{n, n}\left[\left(\prod_{h=0}^{k-1} \mathbf{A}_{t+k-h}\right) \times J_{t+1}\right], \mathbf{A}_{t}$ is the companion matrix of the VAR at time $t ; \mathcal{S}_{n, n}$ is a selection matrix which extracts the first $n \times n$ block of $\left[\left(\prod_{h=0}^{k-1} \mathbf{A}_{t+k-h}\right) \times J_{t+1}\right]$ and $\Psi_{t+k, k-1}^{j}$ is the column of $\Psi_{t+k, k-1}$ corresponding to the $j$-th shock.

When the coefficients are constant and $e_{j, t}=1$ for $t=1$ and zero otherwise, (8) collapse to the traditional impulse response function to unitary structural shocks. In general, $I R_{y}^{j}(t, k)$ depends on the identifying matrix $J_{t}$, the history of the data and the dynamics of the reduced form coefficients up to time $t$.

The structural model (6)-(7) is estimated using Bayesian methods. We specify prior distributions for the parameters and use the available data to compute posterior distributions for the reduced form parameters. Since an analytical expression for the marginal posterior of the parameters of interest is unavailable we use the Gibbs sampler to construct sequences from these distributions. Then, we use the identification restrictions detailed below to recover the posterior distribution of structural shocks and structural parameters. Finally, with these draws we compute posterior distributions for the statistics of interest.

Given the complexity of the estimation approach and heavy notation involved, we collect the details of the construction of the posterior distributions for the structural parameters, the structural shocks and the structural statistics in Appendix A. 


\section{The identification restrictions}

Despite the fact that our empirical model has four variables, we will identify only three structural shocks. We decided to leave one of the reduced form shocks unidentified for two reasons. First, since such a residual shock acts as a buffer, it captures the effects of potentially omitted variables, leaving structural shocks relatively free of these variations in section 5 we show this is indeed the case. Such a separation would not be possible if all VAR shocks are given a structural interpretation. Second, the presence of this shock allows us to examine the reasonableness of our identification procedure. To the extent that important theoretical disturbances, such as labour supply, investment specific or inflation expectations shocks are left out of our analysis, the percentage of the variations in output growth and inflation explained by the identified shocks is a useful thermometer to judge the soundness of our analysis. Table 1 presents our identification restrictions.

Table 1: Identification restrictions

\begin{tabular}{|l|l|l|l|l|}
\hline \hline & Output growth & Inflation & Short rate & Money growth \\
\hline Technology & $\geq 0$ & $\leq 0$ & $\leq 0$ & $\leq 0$ \\
Real Demand & $\geq 0$ & $\geq 0$ & $\geq 0$ & $\geq 0$ \\
Monetary & $\geq 0$ & $\geq 0$ & $\leq 0$ & $\geq 0$ \\
\hline \hline
\end{tabular}

Technology shocks are disturbances displacing the aggregate supply curve, while both real demand and monetary policy shocks are disturbances displacing the aggregate demand curve. In both cases we do not require the other curve to be fixed: because of general equilibrium effects, it is allowed to move, but we require these movements to be small relative to the ones we are interested in. To distinguish between real demand and monetary disturbances we also require that monetary shocks generate liquidity effects (negative comovements between short term nominal rate and money growth) and that government spending shocks produce positive comovements between money growth and short term nominal rates. Since technology shocks must not increase money growth and the nominal rate, they are unlikely to be confused with expectational shocks (see Lubik and Schorfheide (2004)).

While we take these restrictions off-the-shelf, appendix B sketches a DSGE model which generates them for a wide range of values of the parameters, different monetary and fiscal policy rules and for a number of horizons. In this sense, the restrictions we use should be considered robust. Notice also that, since only sign restrictions are employed, the intensity of the effects is allowed to change over time. Our identification scheme, however, does not permit the structural characteristics of the shocks to vary with time, i.e. a monetary disturbance can not generate expected inflation effects in one period and liquidity effects in 
another. When the list of identified shocks is rich enough this should not cause interpretation problems.

There are many ways of imposing sign restrictions. The results we present are obtained using an acceptance sampling scheme, where draws that jointly satisfy the whole set of restrictions are kept and draws that do not are discarded. Alternative schemes, which give different weights to different types of draws, or that allow for the possibility that with one draw only a subset of the shocks is identified, produce qualitatively similar outcomes.

Since the sign restrictions we use are generic, we are free to choose how many responses to constrain for identification purposes. There is an important trade-off to consider when making this choice. When only a few horizons are restricted, shocks with different mediumlong run implications could be confused. As the number of restricted responses increases, the empirical analysis acquires a more structural character, but if restrictions are invalid, inference is inappropriate and standard errors inaccurate. Since this trade-off is highly nonlinear, it is difficult to optimize. We present results obtained imposing restrictions at two horizons (0 and 1$)$, since this choice accounts for both concerns.

The VAR we use is the same for each country: it includes two lags of each variable and an intercept. We maintain as much as possible comparability across countries. For output we use real GDP, for the interest rate a short term 3 month rate and for money a narrow measure (M1 for the US and the Euro area, M0 for the UK). Inflation is computed quarter on quarter and annualized and measures GDP inflation in the US and the Euro area and retail price index inflation for the UK. The sources of the data are the FREDII database at the Fed of St.Louis, the ECB area wide model, and the Bank of England.

\section{The Evidence}

\subsection{The structural dynamics of output growth and inflation}

Figures 1 to 3 present the structural dynamics of output growth and inflation in the US, the Euro area and the UK. We summarize the dynamic features of these two variables with a measure of persistence and one of volatility and report the median and the highest $68 \%$ band of the posterior for these structural statistics. Persistence is measured by the height of the zero frequency of the spectrum; volatility by magnitude of the cumulative spectrum. The sample differs across countries: data runs from 1959:1 to 2004:4 for the US; from 1970:1 to 2002:4 for the Euro area, and from 1963:1 to 2004:4 for the UK.

On average, inflation has been more volatile and persistent in the UK than in the other two countries. However, since different price index series are used, these differences may 
reflect measurement errors. Output growth looks like a white noise in the Euro area; it displays some serial correlation in the UK, and is considerably more positively serially correlated in the US, especially in the late 1990s. Output growth volatility has similar magnitude in the US and the UK; while, probably because of the nature of the data, it is much lower in the Euro area.

There are important common features in the time profile of persistence and volatility of inflation across countries: both inflation volatility and inflation persistence are low in the 1960s; they increase dramatically in the early 1970s and peak in the middle of the decade; they sharply decline up to 1980 and remain roughly at the 1980 level for the rest of the sample, except in the UK, where a small peak in both statistics shows up in the middle of 1980s. The magnitude of the swings is quite large: the peak in all countries is about 3 times as large as the average value after 1980. Posterior standard error bands are tight for US and the UK statistics so that both measures have significantly increased and significantly declined in the sample. For the Euro area error bands are larger and the case for evolving volatility and persistence is much harder to make.

Output growth volatilities show interesting features. In the US and the UK there is a clear U-shaped pattern. Volatility was about $30 \%$ larger in the early part of the sample than in the 1980s and the volatility recorded in 2000 is roughly of the same magnitude as in the late 1960s-early 1970s. In the Euro area, on the other hand, we only observe a marked increase in output growth volatility in the last 10 years of the sample. Output growth persistence shows more heterogeneity across countries. In the US and the UK, there is a considerable decline from the peak of the early 1970s to the through in the early 1980s (50\% or more), while persistence in the Euro area temporarily increases around 1980. In the last part of the sample, output growth persistence shows an increasing trend in the US, and only a hint of an increase in the other two countries. Contrary to what happens for inflation, changes in output growth dynamics are insignificant in all countries.

Overall, estimated US and UK structural inflation dynamics broadly agree with those obtained using reduced form methods (Cogley and Sargent (2005)), and other structural analyses (e.g. Gambetti et al. (2005) and Benati and Mumtaz (forthcoming)), although the specification of the VAR model and the variables used differs. Interestingly, the dynamics of output persistence differ somewhat from the time series characterization of Stock and Watson (2003). 
Table 2 Cross Correlations

\begin{tabular}{|l|l|l|l|l|l|l|}
\hline \hline & US-Euro & US-UK & Euro-UK & US & Euro & UK \\
\hline Inflation Persistence & 0.96 & 0.84 & 0.91 & & & \\
Inflation Volatility & 0.97 & 0.87 & 0.92 & & & \\
\hline Output growth Persistence & 0.62 & 0.80 & 0.51 & & & \\
Output growth Volatility & 0.19 & 0.87 & 0.45 & & & \\
\hline Output growth-inflation persistence & & & & 0.48 & 0.41 & 0.52 \\
Output growth-inflation volatility & & & & 0.54 & -0.29 & 0.15 \\
\hline \hline
\end{tabular}

Table 2, which reports a few cross contemporaneous correlations for the median values of the posterior distributions of the two variables within and across countries, reiterates the presence of important similarities in the cross-country dynamics of inflation (see also Ciccarelli and Mojon (2005) and Mumtaz and Surico (2006)); confirms the presences of an Anglo-Saxon real cycle, documented with other techniques in Canova, et. al. (forthcoming); and highlights that the real Euro area cycle is different, for at least two-thirds of the sample. Interestingly, correlations computed using the domestic dynamics of output growth and inflation are considerably smaller than those obtained using one of the two variables across countries. Hence, while the swings in inflation persistence and volatilities over the last 35 years look like a global phenomenon, those of output growth are still, to some extent, country specific. As a consequence, what explains changes in the dynamics of inflation is unlikely to explain also changes in output growth, both within and across countries.

\subsection{What drives changes in structural volatility and persistence?}

To study what drives the changes documented in figures 1-3, we use a simple decomposition. First, the (time varying) structural MA representation of the VAR in each country can be written as $y_{t}=\sum_{i=1}^{4} \phi_{i t}(\ell) e_{i t}$, where $e_{i t}$ is orthogonal to $e_{i^{\prime} t}, i^{\prime} \neq i$, and where, for simplicity, we have omitted deterministic components from the representation. Second, since the spectrum at frequency $\lambda$ is uncorrrelated with the spectrum at frequency $\lambda^{\prime}$, if $\lambda$ and $\lambda^{\prime}$ are Fourier frequencies, and since structural shocks are independent by construction, the (local) spectrum of $y_{j t}$ at frequency $\lambda$ is $S_{y_{j}}(\lambda)(t)=\sum_{i=1}^{4}\left|\phi_{i t}(\lambda)\right|^{2} S_{e_{i}}(\lambda)(t)$. Given this expression, the contribution to the persistence of $y_{j t}$ of structural shock $i$ is $S_{y_{j}}^{i}(\lambda=0)(t)=$ $\left|\phi_{i t}(\lambda=0)\right|^{2} S_{e_{i}}(\lambda=0)(t)$ and the contribution to the volatility of $y_{j t}$ of structural shock $i$ is $\sum_{\lambda} S_{y_{j}}^{i}(\lambda)(t)$, where $y_{j t}$ is either output growth or inflation. As it is clear from their construction, these measures are comparable to historical decomposition statistics. The latter tells us the relative contribution of different shocks at various forecasting horizons; 
the measures we construct evaluate the contribution of structural shock $i$ to the evolution of the spectrum of $y_{j t}$ at the zero frequency or cumulatively across frequencies.

To start with we would like to mention that the three identified shocks explain a considerable portion of the volatility and of the persistence of the two variables in all countries. For example, in the US, they explain $65-75 \%$ of the persistence of output growth and inflation and $75-85 \%$ of the variance of output growth and inflation on average over the sample, while in the Euro are they explain 55-60\% of the level of output growth persistence and variance and 85-90\% of inflation persistence and variance on average over the sample. Interestingly, these percentages are relatively stable across time and across frequencies: on average over time and across frequencies, the three shocks explain 65-75\% of output growth variability and $70-80 \%$ of inflation variability across countries.

Figure 4 reports the decomposition of interest. The first column considers US statistics, the second Euro area statistics and the third UK statistics. The first row refers to inflation persistence, the second to inflation volatility, the third to output growth persistence and the last one to output growth volatility. In each box, each path represents the time profile which would have materialized if only one type of shock were present.

A few striking features of the figure are worth discussing. First, in each country the contribution of each of the structural shocks to inflation persistence and volatility is similar. Hence, sources of inflation persistence are the same as those of inflation volatility. Second, the sharp increase observed in the 1970s and the subsequent decline in both statistics appear to be primarily due to demand disturbances, even though the relative importance of real demand and monetary shocks differs across countries. Supply shocks, although less crucial on average, also contribute to the swings in US and UK inflation persistence and volatility in this period. Interestingly, all three shocks contribute to the slight increase in inflation volatility and persistence observed in the US and the Euro area in the late 1990s.

Third, variations in output growth persistence and volatility are driven by different shocks in different countries and what drives output growth persistence is often different than what drives output volatility within countries. In the US, supply and real demand shocks are largely responsible for the U-shaped profile of the persistence of output growth, while monetary and supply shocks give to output growth volatility the observed U-shaped profile. In the Euro area, the peak observed just around 1980 in output growth persistence is due to monetary and supply shocks and the increase in output growth volatility in the 1990s is equally due to the three structural shocks, with monetary and real demand shocks showing the largest variations over time. Finally, in the UK the U-shaped pattern in output growth volatility is primarily due to supply disturbances, while all three shocks contribute 
to time variations in output growth persistence.

We would like to stress the novelty of the exercise we conduct. For the US, Canova and Gambetti (2004), Sims and Zha (2006) and Primiceri (2005), provide evidence on the structural dynamics of inflation. However, they do not document the joint dynamics of structural output growth and inflation and sources of time variation have been analyzed, to the best of our knowledge, only in Gambetti et. al. (2005). On the other hand, there is a large literature discussing inflation persistence in the Euro area (see e.g. Gadzinski and Orlandi (2004), O'Really and Whelan (2004) or Marques (2004)), but the evidence is based on univariate, time series and unstructural analyses. Finally, while Benati and Mumtaz (forthcoming) perform a structural analysis of the UK economy, their focus is different and do not report our decomposition.

There are three important conclusions one can draw from the evidence we report. First, both the absolute value and the swings in the magnitude of inflation volatility and persistence in the US and the UK are only partially related to policy shocks. While this evidence is not necessarily in contrasts with the conventional wisdom, which see in the lack of activisms of Central Banks the reason for the surge in inflation of the mid-late 1970, it nevertheless suggests that other macroeconomic shocks played a possibly more important role in shaping inflation dynamics over the last 35 years. Second, the determinants of output growth dynamics are different across countries. Third, sources of output growth and inflation variations differ within a country and what drives output volatility does not necessarily drive output persistence.

\subsection{Does the structure of the economy change?}

To go beyond the documentation of the contribution of different structural shocks to the statistics of interest and to understand whether changes in the structure, or changes in the distribution from which structural shocks are drawn are responsible for the observed variations in output growth and inflation dynamics, we need to separate the two sources of variations and analyze their relative contribution in isolation. This is easy to do. In fact, changes in the transmission of shocks (i.e. time variations in $\phi_{i t}$ ) reflect changes in the structure while changes in the cumulative spectrum of structural shocks $\left(\int_{\lambda} S_{e_{i}}(\lambda)(t)\right)$ capture variations in the distribution from which structural shocks are drawn.

We report the time profile of output growth and inflation median responses to our three structural shocks in the three countries in figures 5 to 7 . We have omitted standard error bands from the figures because they visually complicate the pictures and add little to our

points. Since the magnitude of the impulse is the same in every period, the evolution of 
these responses provides visual evidence of the changes in the transmission of shocks in isolation from the changes in the posterior distribution of the shocks. Moreover, since the magnitude of the impulse is also the same across countries, a comparison across figures gives us an idea of the size of the structural heterogeneities present in the three economies and of their evolution.

From the figures it appears that time variations in the structure are somewhat limited in magnitude, but when they occur they tend to display similarities across countries. For example, while the shape of output growth responses to the three shocks has hardly changed over time, one can notice a significant increase in the contemporaneous output growth response to demand shocks since the early 1980s in all countries. Responses of inflation display some more evidence of time variations. In the US in the mid-late 1970s, inflation responses to all shocks were much more persistent than at any other date and the magnitude of the differences is substantial. Furthermore, the impact effect of demand shocks on inflation has somewhat permanently increased since the late 1980s. In the UK, a similar effect is present in the 1970s, in particular, in the responses to demand disturbances. Noticeable is also the change in the lagged responses to monetary shocks: in the last few years the deep dip present in the 1970s disappears. In the Euro area contemporaneous responses to demand shocks increase over time and the profile of the first few responses to monetary shocks displays visible time variations. Interestingly, all types of shocks have a larger effect on output growth in the US and the UK than in the Euro area but the inflation effects are comparable. Hence, the real side of the Euro economy appears to be much more sluggish in response to shocks than the one of the US or the UK.

To the best of our knowledge, the increase responsiveness of US output growth to demand shocks in the 1990s has not been documented before. Such an effect could be explained in a variety of ways. In a flexible price model, demand shocks exercise their effects on real activity because of wealth effects. Hence, the increased responsiveness of output growth to demand shocks could be accounted for by an increased elasticity of labour supply and/or a stronger habit persistence mechanism. In a sticky price model, higher responsiveness of output growth to demand conditions is obtained either via an increase in the stickiness of the price level or via a reduction of the costs associated with hiring capital and labour, with the second alternative being probably more attractive to explain the US experience. Hence, regardless of the model one uses, variations in the way labour markets work could account for both the temporary and the more long run changes in the US economy.

The 1970s in the UK are also an interesting case to study since demand shocks (and, to some extent, monetary shocks) produce time varying responses in inflation but not in 
output growth. As far as we know, only Khan and Rudolf (2005) have studied why such a phenomenon may have appeared and attribute it to changes in the wage indexation mechanism and in the stock of consumer habits.

Jaimovich and Rebelo (2006) have tried to link variations in output volatility with changes in the nature of news. In particular, they claim that a larger volume of news induces a better forecast of output growth and, therefore, a reduction of output volatility. While such an explanation can account for the decrease of output volatility in the 1980 s, it has hard time to explain why volatility and persistence jointly decreased over the period. Moreover, to explain the 1990s, we need that either the volume of news declines or that news become noisier, both of which seem unlikely. Our finding that demand shocks exercise a much stronger effect on output growth in the period seems more plausible.

All in all, we conclude that, excluding the 1970s, and the 1990s in the US, changes in the structure have been somewhat limited in all three countries and trends in one direction or another are largely absent.

\subsection{Does the volatility of the structural shocks change?}

Next, we examine the magnitude and the profile of time variations in the volatility of structural shocks. We plot the estimated posterior median of the volatility of the three structural shocks in figures 8 to 10. For each country, real demand shocks are those associated with the first structural equation (normalized on output), supply shocks with the second structural equation (normalized on inflation) and the monetary policy shocks with the third structural equation (normalized on the nominal interest rate).

As it was the case for the transmission of structural shocks, the time profile of the variability of the three structural shocks displays some interesting similarities across countries. For example, in all countries, the structural volatilities of the three shocks are somewhat smaller since the 1980s, while in the 1970s the volatility of monetary shocks was high relative to historical standards.

In the US, the variability of real demand and monetary shocks has an important time trend. Since the variability of demand shocks is the largest of all (demand shocks are twice as volatile as monetary policy shocks and up to 4 times as volatile as supply shocks), and displays a permanent decrease in the early 1980s, the increased stability in inflation and output growth probably results from a sizable decline in the volatility of these shocks. The variability of monetary policy shocks also declines. However, the fall is comparatively smaller, it predates the Great Inflation period and appears to be unrelated to changes in inflation expectations, which start declining only in the early 1980s. We provide more 
evidence on this issue in the next subsection. This evidence is in contrast with the one of Arias, et. al. (2006) who, using a business cycle accounting exercise, claim that the decline in US output volatility is almost entirely explained by a decline in the volatility of TFP shocks. Since it is well known that TFP shocks capture a number of demand shocks, their technology shocks may not have much to do with those we recover.

For the Euro area, trend variations in the volatility of structural shocks are visible only for real demand disturbances. Interestingly, there is a negative correlation between the time profile of the variability in monetary policy and supply shocks, on one hand, and real demand shocks, on the other. For this reason, the increase volatility of output growth in the 1990s and the high level of inflation persistence and variability in the 1970s are largely coincident with the increase in the volatility of supply and monetary policy disturbances.

For the UK, trend variations in the volatility of structural shocks are, by and large, absent. The Great Inflation of the 1970s is associated with an increase in the volatility of supply and monetary policy shocks, while the increased volatility of demand shocks accounts for the increase in inflation persistence and volatility observed in the mid-1980s. Benati and Mumtaz (2006) claim that had the volatility of shocks other than monetary policy been unchanged, the Great Inflation would not have occurred. Our results disagree somewhat with this interpretation: we confirm that the variability of all shocks considerably increased in the 1970s. However, the increase in the variability of supply and demand shocks is dwarfed by the increase in the variability of monetary policy shocks, which grew by about $50 \%$ from the mid 1960s to the mid 1970s.

To summarize, we detect changes in the structure of the economies as well as changes in the volatility of structural disturbances in all countries. Changes in the structure are noticeable in the responses of inflation to real demand shocks. Changes in the volatility of the structural shocks have been more pervasive and appear to be coincident with the changes in persistence and volatilities documented in figures 1 to 3 . In general, it is impossible to account for the Great Inflation of the 1970s and for the substantive output growth of the 1990s with one single explanation. In the US changes in the transmission and in the variability of demand shocks appear to be important; in the Euro area changes in the transmission and the volatility of monetary policy shocks and in the volatility of supply shocks matter; in the UK changes in the transmission of demand shocks and in the volatility of supply and of policy shocks account for output growth and inflation dynamics. 


\subsection{The nature of the structural shocks}

Although we have argued that our shocks are structural, there is always the possibility that they are mongrels and capture a number of factors, going from omitted variables to shocks with similar characteristics, and this is particularly important in small scale VAR systems like the ones we are considering here. In addition, it is possible that our econometric approach is weak in detecting local alternatives and may be attributing to shock volatilities structural variations in the transmission or vice versa. We have therefore examined how our three structural shocks relate, for example, to inflation expectations, extracted from the slope of the domestic term structure of interest rates assuming a constant real interest rate throughout the period, and to real commodity price shocks, computed as residuals of $\operatorname{AR}(3)$ univariate regressions.

Table 3: Cross Correlations

\begin{tabular}{|l|l|l|l|l|l|l|}
\hline \hline & \multicolumn{2}{l|}{ Inflation Expectations } & \multicolumn{3}{l|}{ Commodity prices shocks } \\
\hline \hline & -1 & 0 & 1 & -1 & 0 & 1 \\
\hline US Supply shocks & 0.16 & 0.28 & 0.39 & -0.16 & -0.07 & -0.00 \\
US Demand shocks & -0.23 & -0.10 & 0.01 & 0.12 & 0.17 & 0.21 \\
US Monetary shocks & -0.16 & -0.05 & 0.04 & -0.08 & -0.03 & 0.00 \\
\hline Euro Supply shocks & -0.03 & 0.11 & 0.25 & -0.07 & -0.00 & -0.07 \\
Euro Demand shocks & -0.10 & 0.05 & 0.21 & 0.08 & 0.15 & 0.22 \\
Euro Monetary shocks & -0.13 & -0.09 & 0.04 & 0.14 & 0.17 & 0.27 \\
\hline UK Supply shocks & -0.17 & 0.02 & 0.11 & -0.13 & -0.05 & 0.02 \\
UK Demand shocks & -0.10 & 0.05 & 0.19 & 0.04 & 0.10 & 0.16 \\
UK Monetary shocks & -0.16 & -0.00 & 0.13 & -0.04 & 0.02 & 0.09 \\
\hline \hline
\end{tabular}

Lubik and Schorfheide (2004) have shown that when indeterminacies are present, shocks to inflation expectations matter for the dynamics of output growth and inflation and they induce effects on these two variables which are roughly equivalent to those generated by supply shocks. It is therefore particularly important to check that our structural shocks do not correlate with changes in inflation expectations. We have already argued that our choice of identification restrictions should, in principle, avoid this confusion. Table 3 confirms this point: except for the US, the contemporaneous correlation of all shocks with changes in inflation expectations is insignificant. In addition, there are reasons to believe that even for the US, structural supply shocks are relatively free of variations related to inflation expectations. The common wisdom in fact suggests that inflation expectations were an important driving force for the inflation dynamics in the 1970s but not afterwards. Therefore, if our supply shocks proxy for changes in inflation expectations, we should observe large changes 
in the responses to these shocks and/or large changes in their variability. However, as we have documented, supply shocks explain little of the dynamics of US inflation in the 1970s and 1980s and their variability is roughly unchanged over the whole sample period.

Our measure of inflation expectations is also uncorrelated with monetary policy shocks at leads and lags in all three countries and this is true even if we restrict attention to the 1990s. Therefore, if inflation expectations independently matter for describing central banks' behaviour, they must enter the policy rule with a very small coefficient.

Our structural shocks appear to be also largely uncorrelated with shocks to the real price of commodities. In particular, our estimated supply shocks do not significantly comove with such shocks, while lagged shocks to the real price of commodities correlate with real demand shocks in the US and real demand and monetary policy shocks in the Euro area.

Are shocks driving the three economies common? To investigate this possibility we have computed cross country contemporaneous correlation among shocks of the same type. The largest correlation is between real demand shocks in US and Euro area and it is a mere 0.13. Lagged correlations are somewhat larger: for example, current real demand shocks in the Euro area are significantly correlated with one period lagged demand shocks in the US (point estimate is 0.26) and current supply shocks in the UK are marginally correlated with one period lagged supply shocks in the US (point estimate is 0.21 ). On the other hand, Euro area and UK shocks appear to be unrelated at both leads and lags.

To sum up, the structural shocks we have recovered do not stand-in for inflation expectations, an important variable omitted from the estimated specification. Also, they hardly correlate with shocks to the real price of commodities and display a highly idiosyncratic nature across countries. Hence, the similarities displayed by inflation (and output growth) dynamics across countries, can not be the result of common shocks.

\section{Conclusions}

This paper investigates the nature and the causes of the structural changes in output growth and inflation dynamics in the US, the UK and the Euro area. We contribute to the existing literature in two distinct ways: first, we jointly examine the dynamics of output growth and inflation from a structural point of view. Second, we compare sources of structural time variations of output growth and inflation dynamics across countries.

We address three main questions. First, are there structural changes in the volatility and the persistence of output growth and inflation? Are they comparable in size and timing across countries? Second, what are the reasons for these changes? Do they reflect time 
variations in the transmission or in the size and the nature of structural shocks? Third, are there common sources of variations across countries?

The results of our investigation can be summarized as follows. We show that there are important similarities in the structural dynamics of inflation across countries over the last 35 years. However, structural output growth dynamics acquired significant cross country similarities only since the early 1990s.

Swings in the magnitude of volatilities and persistence are typically accounted for by a combination of all three structural shocks. We document that sources of inflation persistence and volatility are similar and that sources of output growth dynamics vary across countries. Within a country, sources of output growth and inflation variations are different.

Time variations in the structure of the three economies appear to have been limited in time and scope and permanent shifts, in one direction or another, are largely absent. The 1970s in the US and the UK and the 1990s in the US are notable exceptions. Changes in the volatilities of structural shocks are as least as important as changes in the structure to account for the evidence. In general, it is impossible to explain the Great Inflation of the 1970s and the substantive output growth of the 1990s with one single explanation. In the US changes in the transmission and in the variability of demand shocks appear to be important; in the Euro area changes in the transmission and the volatility of monetary policy shocks and in the volatility of supply shocks matter; in the UK changes in the transmission of demand shocks and in the volatility of supply and monetary policy shocks account for the observed output growth and inflation dynamics.

There are many interesting questions which, for reasons of space, we have left out of the paper. For example, one could investigate the relationship between monetary policy activism and the dynamics of output growth and inflation and therefore shed light on the bad luck vs. bad policy controversy, or examine how the slope of the Phillips curve is related to the shocks we have recovered. One could also try to understand why the Euro area is so different from the US and the UK, at least until the 1990s, and why output growth dynamics appear to converge after that date. We leave all these issues for future research. 


\section{Appendix A}

This appendix describes the estimation approach we use in the paper.

Let $T$ be the end of the estimation sample and $K_{1}$ be the number of periods for which the identifying restrictions must be satisfied. Let $H_{T}=\rho\left(\varphi_{T}\right)$ be a matrix whose columns represent orthogonal points in the hypershere and let $\varphi_{T}$ be a vector in $R^{6}$ whose elements are $U[0,1]$ random variables. Let $\mathcal{M}_{T}$ be the set of impulse response functions satisfying the restrictions and let $F\left(\mathcal{M}_{T}\right)$ be an indicator function which is one if the identifying restrictions are satisfied, that is, if $\left(\Psi_{T+1,0}^{i}, \ldots, \Psi_{T+K_{1}, K_{1}-1}^{i}\right) \in \mathcal{M}_{T}$, and zero otherwise. The joint prior for $\left(\theta^{T+K_{1}}, \Sigma_{T}, \Omega_{T}, H_{T}\right)$ is

$$
p\left(\theta^{T+K_{1}}, \Sigma_{T}, \Omega_{T}, H_{T}\right)=p\left(\theta^{T+K} \mid \Sigma_{T}, \Omega_{T}\right) p\left(\Sigma_{T}, \Omega_{T}\right) F\left(\mathcal{M}_{T}\right) p\left(H_{T}\right)
$$

where $p\left(\theta^{T+K} \mid \Sigma_{T}, \Omega_{T}\right) \propto \prod_{t=0}^{T+K} I\left(\theta_{t}\right) \prod_{t=1}^{T+K} f\left(\theta_{t} \mid \theta_{t-1}, \Sigma_{t}, \Omega_{t}\right)$ is truncated normal.

We assume that $\Sigma_{0}$ and $\Omega_{0}$ have independent inverse Wishart distributions with scale matrices $\bar{\Sigma}_{0}, \bar{\Omega}_{0}$ and degrees of freedom $\nu_{01}$ and $\nu_{02}$, and set $\Omega_{t}=\alpha_{1} \Omega_{t-1}+\alpha_{2} \Omega_{0}, \forall t$, where $\alpha_{1}, \alpha_{2}$ are parameters. We also assume that $\theta_{0}$ is truncated Gaussian, independent of $\Sigma_{T}$ and $\Omega_{T}$, i.e. $f\left(\theta_{0}\right) \propto I\left(\theta_{0}\right) N(\bar{\theta}, \bar{P})$. Finally, $p\left(H_{T}\right)$ is assumed to be uniform.

We "calibrate" prior parameters using estimates obtained from fixed coefficient VARs. We set $\bar{\theta}$ equal to the point estimates of the coefficients and $\bar{P}$ to the estimated covariance matrix. $\bar{\Sigma}_{0}$ is equal to the sum of squares of VAR innovations, $\bar{\Omega}_{0}=\varrho \bar{P}$ and $\nu_{01}=\nu_{02}=4$ (so as to make the prior close to non-informative). We examined two values, $\varrho=0.0001$ and 0.001 , which imply that a-priori time variation accounts for roughly, 1 or $10 \%$ of the total coefficients standard deviation. Results are independent of this choice.

Since the statistics we compute depend on $\Psi_{T+k, k}, S$ and $H_{T}$, we first characterize the posterior of $\theta^{T+K}, \Sigma_{T}, \Omega_{T}$, which are used to construct $\Psi_{T+k, k}$ and $S$, and then describe how to sample from them.

To draw posterior sequences we need $p\left(H_{T}, \theta_{T+1}^{T+K}, \theta^{T}, \Sigma_{T}, \Omega_{T} \mid y^{T}\right)$, which is analytically intractable. Using basic laws of probability, we can rewrite this posterior as:

$$
\begin{aligned}
p\left(H_{T}, \theta_{T+1}^{T+K}, \theta^{T}, \Sigma_{T}, \Omega_{T} \mid y^{T}\right) \propto & {\left[\prod_{t=T}^{T+K} I\left(\theta_{t}\right) f\left(\theta_{T+1}^{T+K} \mid \theta^{T}, \Sigma_{T}, \Omega_{T}\right) I\left(\theta^{T}\right) p_{u}\left(\theta^{T}, \Sigma_{T}, \Omega_{T} \mid y^{T}\right)\right] } \\
& F\left(\mathcal{M}_{T}\right) p\left(H_{T}\right)
\end{aligned}
$$

where $p_{u}\left(\theta_{T}, \Sigma_{T}, \Omega_{T} \mid y^{T}\right) \equiv f\left(y^{T} \mid \theta^{T}, \Sigma_{T}, \Omega_{T}\right) f\left(\theta^{T} \mid \Sigma_{T}, \Omega_{T}\right) p\left(\Sigma_{T}, \Omega_{T}\right)$ is the posterior density of the parameters when no restrictions are imposed.

Given (10), draws for the structural parameters can be obtained as follows: 
1. Draw $\left(\theta^{T}, \Sigma_{T}, \Omega_{T}\right)$ from $p_{u}\left(\theta^{T}, \Sigma_{T}, \Omega_{T} \mid y^{T}\right)$ via the Gibbs sampler (see below). Apply the filter $I\left(\theta^{T}\right)$ to eliminate draws which produce explosive systems

2. Given $\left(\theta^{T}, \Sigma_{T}, \Omega_{T}\right)$, draw future states $\theta_{T+1}^{T+K}$, i.e. draw $u_{T+k}$ from $N\left(0, \Omega_{T}\right)$ and iterate in $\theta_{T+k}=\theta_{T+k-1}+u_{T+k}, K$ times. Apply the filter $I\left(\theta_{T+1}^{T+K}\right)$.

3. Draw $\varphi_{i, T}, i=1, \ldots, 6$, from a $U[0,1]$. Draw $H_{T}=\rho\left(\varphi_{T}\right)$.

4. Given $\Sigma_{-}$, find the matrix $S_{T}$, such that $\Sigma_{T}=S_{T} D S_{T}^{\prime}$. Construct $J_{T}^{-1}$.

5. Compute $\left(\Psi_{T+1,0}^{i, \ell}, \ldots, \Psi_{T+K, K-1}^{i, \ell}\right)$ for each replication $\ell$. Apply the filter $F\left(\mathcal{M}_{T}\right)^{\ell}$ and keep the draws that satisfy the identification restrictions.

To draw reduced form parameters (step 1 of the algorithm) we iterate on two steps (see e.g. Cogley and Sargent (2005)). In the first step, conditional on $\left(y^{T}, \Sigma_{T}, \Omega_{T}\right)$, $p_{u}\left(\theta^{T} \mid y^{T}, \Sigma_{T}, \Omega_{T}\right)=f\left(\theta_{T} \mid y^{T}, \Sigma_{T}, \Omega_{T}\right) \prod_{t=1}^{T-1} f\left(\theta_{t} \mid \theta_{t+1}, y^{t}, \Sigma_{t}, \Omega_{t}\right)$ and since all densities on the right hand side are Gaussian, their conditional means and variances can be computed using a simulation smoother. In the second step, given $\theta_{T}$ and the data, $p\left(\Sigma_{t} \mid \theta^{T}, y^{T}\right)=$ $I W\left(\Sigma_{1 t}^{-1}, \nu_{11}\right) ; p\left(\Omega_{t} \mid \theta^{T}, y^{T}\right)=I W\left(\Omega_{1 t}^{-1}, \nu_{12}\right)$ where $\Sigma_{1 t}=\bar{\Sigma}_{0}+\sum_{t=1}^{T} \varepsilon_{t} \varepsilon_{t}^{\prime}, \Omega_{1 t}=\bar{\Omega}_{0}+$ $\sum_{t=1}^{T} u_{t} u_{t}^{\prime}, \nu_{11}=\nu_{01}+T, \nu_{12}=\nu_{02}+T$.

In our exercises we used up to 30000 iterations for each $T$ and found that convergence was relatively easy and obtained in less than 4000 draws. We keep one every eight of the remaining draws, discard those generating explosive paths and those failing to generate the identification restrictions. In the end we are left with roughly 500 draws for each $T$. Given a draw for $\left(\theta^{T+K}, \Sigma, \Omega_{T}, H_{T+1}\right)$ we calculate $\Psi_{T+k, k-1}$, compute the posterior median and the $68 \%$ highest credible set out of its posterior at each horizon $k$.

To compute the posterior distribution for spectra, we use the fact that the spectrum of $y_{t}$ at Fourier frequencies $\lambda$ is $S_{y}(\lambda)=\frac{1}{2 \pi} \sum_{i=1}^{n}\left|\phi_{i t}(\lambda)\right|^{2} \sigma_{i t}^{2}$, where $\left|\phi_{i t}(\lambda)\right|^{2}=\left|\sum_{j} \phi_{i t} e x p^{-i \lambda j}\right|^{2}$ is the squared Fourier transform of the MA coefficients and $\sigma_{i t}^{2}$ the variance of the structural shocks at time $t$. Therefore, given draws for $\phi_{i t}(\ell)$ and $\sigma_{i t}^{2}$, we can easily compute posterior distributions for a measure of persistence $S_{y}(\lambda=0)$ and for volatilities $\sum_{\lambda} S_{y}(\lambda)$.

\section{Appendix B}

This appendix briefly sketches the features of a dynamic stochastic general equilibrium model which produces the identifying restrictions we use in the paper.

The economy features a representative household, a continuum of firms, a monetary and a fiscal authority. The fiscal authority spends for both consumption and investment pur- 
poses. Government consumption may yield utility for the agents and government investment may alter the productive capacity of the economy.

Households maximize $E_{0} \sum_{t=0}^{\infty} \beta^{t} \frac{\left[\left(a C_{t}^{p \frac{\varsigma-1}{\varsigma}}+(1-a) C_{t}^{g \frac{\varsigma-1}{\varsigma}}\right)^{\frac{\varsigma}{\varsigma-1}}\left(1-N_{t}\right)^{1-\theta_{n}}\right]^{1-\sigma}-1}{1-\sigma}+\frac{1}{1-\vartheta_{M}}\left(\frac{M_{t}}{p_{t}}\right)^{1-\vartheta_{M}}$ choosing sequences for private consumption, $C_{t}$, hours, $N_{t}$, private capital, $K_{t+1}^{p}$, nominal state-contigent bonds, $D_{t+1}$, nominal balances, $M_{t+1}$, and government bonds, $B_{t+1}$. Here $0<\beta<1$ is the subjective discount factor, $\sigma>0$ is a risk aversion parameter, $0<\varsigma \leq \infty$ regulates the degree of substitutability between private and public consumption and $0<$ $a \leq 1$ is the share of public and private goods in consumption. Time is normalized to one at each $t$. We assume $C_{t}^{p}=\left[\int_{0}^{1} C_{i t}^{p}(i)^{\frac{\lambda-1}{\lambda}} d i\right]^{\frac{\lambda}{\lambda-1}} ; C_{t}^{g}=\left[\int_{0}^{1} C_{i t}^{g}(i)^{\frac{\lambda-1}{\lambda}} d i\right]^{\frac{\lambda}{\lambda-1}}$ and $\lambda>1$ measures the elasticity of substitution between types of goods. Maximization is subject to the sequence of constraints:

$$
\begin{array}{r}
P_{t}\left(C_{t}^{p}+I_{t}^{p}\right)+E_{t}\left\{Q_{t, t+1} D_{t+1}\right\}+R_{t}^{-1} B_{t+1}+M_{t+1} \leq \\
\left(1-\tau^{l}\right) P_{t} w_{t} N_{t}+\left[r_{t}-\tau^{k}\left(r_{t}-\delta^{p}\right)\right] P_{t} K_{t}^{p}+D_{t}+B_{t}-T_{t} P_{t}+M_{t}+\Xi_{t}
\end{array}
$$

where $\left(1-\tau^{l}\right) P_{t} w_{t} N_{t}$, is the after tax nominal labour income, $\left[r_{t}-\tau^{k}\left(r_{t}-\delta^{p}\right)\right] P_{t} K_{t}^{p}$ is the after tax nominal capital income (allowing for depreciation), $\Xi_{t}$ are nominal profits distributed by firms (which are owned by consumers), $T_{t} P_{t}$ are lump-sum taxes, $D_{t+1}$ are holdings of state-contingent nominal bonds, paying one unit of currency in period $t+1$ if a specified state is realized, and $Q_{t, t+1}$ is their period- $t$ price. Finally, $R_{t}$ is the gross return on a one period government bond $B_{t}$. Private capital accumulates according to:

$$
K_{t+1}^{p}=I_{t}^{p}+\left(1-\delta^{p}\right) K_{t}^{p}-\nu\left(\frac{K_{t+1}^{p}}{K_{t}^{p}}\right) K_{t}^{p}
$$

where $0<\delta^{p}<1$ is a constant depreciation rate, $\nu\left(\frac{K_{t+1}^{p}}{K_{t}^{p}}\right)=\frac{b}{2}\left[\frac{K_{t+1}^{p}-\left(1-\delta^{p}\right) K_{t}^{p}}{K_{t}^{p}}-\delta^{p}\right]^{2}$ and $b \geq 0$ determines the size of the adjustment costs.

Firm $j$ produces output according to the production function:

$$
Y_{t j}=\left(Z_{t} N_{t j}^{p}\right)^{1-\alpha}\left(K_{t j}^{p}\right)^{\alpha}\left(K_{t}^{g}\right)^{\mu}
$$

where $K_{t j}^{p}$ and $N_{t j}^{p}$ are private capital and labour inputs hired by firm $j, Z_{t}$ is an aggregate technology shock and $K_{t}^{g}$ is the stock of public capital. Government capital inputs is taken as given and $\mu \geq 0$ regulates how public capital affects private production.

Since firms are perfectly competitive in the input markets, marginal costs are:

$$
M C_{t}=\frac{1}{\alpha^{\alpha}(1-\alpha)^{1-\alpha}} Z_{t}^{\alpha-1} K_{t}^{g(-\mu)} w_{t}^{1-\alpha} r_{t}^{\alpha} P_{t}
$$


Firms are monopolistic competitors in the goods markets. At each $t$, each producer is allowed to reset her price with a constant probability, $(1-\gamma)$, independently of the time elapsed since the last adjustment. Hence, she chooses her new price, $P_{t j}^{*}$, to maxi-

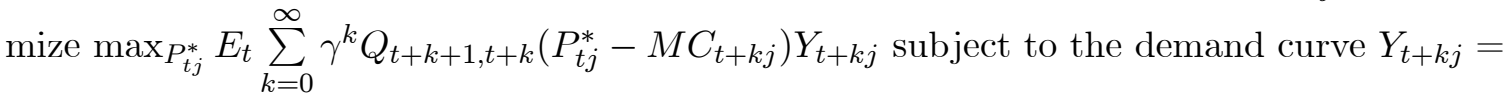
$\left(\frac{P_{t j}^{*}}{P_{t+k}}\right)^{-\lambda} Y_{t+k}$. Optimization implies

$$
\sum_{k=0}^{\infty} \gamma^{k} E_{t}\left\{Q_{t+k+1, t+k} Y_{t+k j}\left(P_{t j}^{*}-\frac{\lambda}{\lambda-1} \frac{1}{1-\tau^{\lambda}} M C_{t+k}\right)\right\}=0
$$

where $\tau^{\lambda}=-(\lambda-1)^{-1}$ is a subsidy that, in equilibrium, eliminates the monopolistic competitive distortion. Given the pricing assumption, the aggregate price index is

$$
P_{t}=\left[\gamma P_{t-1}^{1-\lambda}+(1-\gamma) P_{t}^{* 1-\lambda}\right]^{\frac{1}{1-\lambda}}
$$

When all firms can reset the price at each $t$, prices become flexible and:

$$
P_{t}=\frac{\lambda}{\lambda-1} \frac{1}{1-\tau^{\lambda}} M C_{t}, \quad \forall t
$$

Government's income consists of seigniorage, tax revenues minus subsidies to the firms and proceeds from new debt issue; expenditures consist of consumption and investment purchases and repayment of debt. The government budget constraint is:

$$
P_{t}\left(C_{t}^{g}+I_{t}^{g}\right)+\tau^{\lambda} P_{t} Y_{t}-\tau^{l} w_{t} P_{t} N_{t}-\tau^{k}\left(r_{t}-\delta^{p}\right) P_{t} K_{t}^{p}-P_{t} T_{t}+B_{t}+M_{t}=R_{t}^{-1} B_{t+1}+M_{t+1}
$$

where $I_{t}^{g}$ is government's investments. The government capital stock evolves according to:

$$
K_{t+1}^{g}=I_{t}^{g}+\left(1-\delta^{g}\right) K_{t}^{g}-\nu\left(\frac{K_{t+1}^{g}}{K_{t}^{g}}\right) K_{t}^{g}
$$

where $0<\delta^{g}<1$ is a constant and $\nu($.$) is the same as for the private sector and I_{t}^{g}$ is stochastic. In order to guarantee a non-explosive solution for debt (see e.g., Leeper (1991)), we assume a tax rule of the form:

$$
\left.\frac{T_{t}}{T^{s s}}=\left[\left(\frac{B_{t}}{Y_{t}}\right) /\left(\frac{B^{s s}}{Y^{s s}}\right)\right)\right]^{\phi_{b}}
$$

where the superscript $s s$ indicates steady states. Finally, there is an independent monetary authority which sets the nominal interest rate according to the rule:

$$
\frac{R_{t}}{R^{s s}}=\left(\frac{\pi_{t}}{\pi^{s s}}\right)^{\phi_{\pi}} u_{t}
$$

where $\pi_{t}$ is current inflation and $u_{t}$ is a monetary policy shock. Given this rule, the authority stands ready to supply nominal balances that the private sector demands. 
We assume that the exogenous processes $S_{t}=\left[Z_{t}, C_{t}^{g}, I_{t}^{g}, u_{t}\right]^{\prime}$, evolve according to

$$
\log \left(S_{t}\right)=\left(I_{4}-\varrho\right) \log (\bar{S})+\varrho \log \left(S_{t-1}\right)+V_{t}
$$

where $I_{4}$ is a $4 \times 4$ identity matrix, $\varrho$ is a $4 \times 4$ diagonal matrix with all the roots less than one in modulus, $\bar{S}$ is the mean of $S$ and the $4 \times 1$ innovation vector $V_{t}$ is a zero-mean, white noise process. Gambetti et. al. (2005) show that, when parameters are selected randomly in ranges reported in table A.1, the model jointly generates the sign restrictions we use for identification in at least $68 \%$ of the cases in response to the four types of shocks.

Table A.1: Parameter values or ranges

\begin{tabular}{|l|l|l|}
\hline \hline$\beta$ & discount factor & 0.99 \\
$(B / Y)^{s s}$ & steady state debt to output ratio & 0.3 \\
\hline$\sigma$ & risk aversion coefficient & {$[0.5,6.0]$} \\
$1-a$ & share of public goods in consumption & {$[0.0,0.15]$} \\
$\varsigma$ & elasticity of substitution public/private goods & {$[0.5,3.0]$} \\
$\theta_{n}$ & preference parameter & {$[0.1,0.9]$} \\
$b$ & adjustment cost parameter & {$[0.1,10]$} \\
$\delta^{p}$ & private capital depreciation rate & {$[0.013,0.05]$} \\
$\delta^{g}$ & public capital depreciation rate & {$[0.010,0.03]$} \\
$\mu$ & productivity of public capital & {$[0,0.05]$} \\
$\alpha$ & capital share & {$[0.2,0.4]$} \\
$\tau^{l}$ & average labour tax rate & {$[0,0.3]$} \\
$\tau^{k}$ & average capital tax rate & {$[0,0.2]$} \\
$\left(C^{g} / Y\right)^{s s}$ & steady state $C^{g} / Y$ ratio & {$[0.07,0.12]$} \\
$\left(I^{g} / Y\right)^{s s}$ & steady state $I^{g} / Y$ ratio & {$[0.02,0.04]$} \\
$\phi_{\pi}$ & Taylor's coefficient & {$[0.1,0.4]$} \\
$\phi_{b}$ & coefficient on debt rule & {$[1.05,2.25]$} \\
$\gamma$ & degree of price stickiness & {$[0.0,0.85]$} \\
$\lambda$ & elasticity of substitution between varieties & {$[7.0,8.0]$} \\
$\vartheta_{M}$ & elasticity of money demand & {$[1.0,10]$} \\
$\rho_{C_{g}}$ & persistence of $C_{t}^{g}$ shock & {$[0.6,0.9]$} \\
$\rho_{I_{g}}$ & persistence of $I_{t}^{g}$ shock & {$[0.6,0.9]$} \\
$\rho_{Z}$ & persistence of $Z_{t}$ shock & {$[0.8,0.95]$} \\
$\rho_{u}$ & persistence of $u_{t}^{R}$ shock & {$[0.7,0.9]$} \\
\hline \hline & & \\
\hline
\end{tabular}

Also, since the dynamics induced by government expenditure and government investment shocks on the four variables of interest are qualitatively identical, we lump them together as real demand shocks in the empirical analysis. 


\section{References}

Arias, A., Hansen, G. and Ohanian, L. (2006) Why have business cycle fluctuations become less volatile?, NBER Working Paper No. 12079.

Batini, N. (2002) Euro area inflation persistence, ECB Working Paper No. 201.

Benati L. (2004) "Evolving Post WWI UK economic performance", Journal of Money Banking and Credit, vol. 36, pp. 691-717.

Benati, L. and Mumtaz, H. (forthcoming) "The great stability in the UK: Good policy or good luck?", Journal of Money, Banking and Credit.

Blanchard, O., J. and Simon, J. (2000), "The long and large decline in U.S. output volatility", Brookings Papers on Economic Activity, vol. 1, pp. 135-147.

Canova, F., Ciccarelli, M. and Ortega, E. (forthcoming) "Similarities and convergence in G-7 cycles", Journal of Monetary Economics.

Canova, F. and Gambetti, L. (2004) "Structural changes in the US economy: Bad luck or bad policy?", CEPR Working Paper No. 5457.

Ciccarelli, M. and Mojon, B. (2005) "Global inflation," ECB Working Paper No. 537

Clarida, R., Gali, J. and Gertler, M. (2000) "Monetary policy rules and macroeconomic stability: Evidence and some theory", Quarterly Journal of Economics, vol. CXV, pp. 147-180.

Cogley, T. and Sargent,T., J. (2001) "Evolving post-world war II U.S. inflation dynamics", NBER Macroeconomic Annual, vol. 16, pp. 331-373

Cogley, T. and Sargent, T., J. (2005) "Drifts and volatilities: Monetary policies and outcomes in the post WWII U.S. ", Review of Economic Dynamics, vol. 8, pp. 262-302.

Gadzinski, G. and Orlandi, F. (2004)" Inflation persistence in the European Union, the Euro area and the US", ECB Working Paper No. 414.

Gallant, R., Rossi, P. and Tauchen, G. (1993), "Non linear dynamic structures", Econometrica, vol. 61, pp. 871-907.

Gambetti, L., Pappa, E. and Canova, F. (2005), "Structural changes in the US economy: What explains the changes?", CREI manuscript.

Gordon, R. (2004) "Two Centuries of economic growth: Europe chasing the American frontier", NBER Working Paper No. 10662.

Khan, H. and Rudolf, B. (2005) "Stability of estimated parameters in a DSGE model", Bank of England manuscript.

Koop, G. (1996), "Parameter uncertainty and impulse response analysis", Journal of Econometrics, vol. 72, pp. 135-149. 
Koop, G., Pesaran, H. and Potter, S. (1996), "Impulse response analysis in non-linear multivariate models", Journal of Econometrics, vol. 74, pp. 119-147.

Jaimovich, N. and Rebelo S. (2006), "Can news about the future drive the Business Cycle?", Northwestern University manuscript.

Leeper, E. (1991), "Equilibria under Active and Passive Monetary and Fiscal Policies," Journal of Monetary Economics, vol. 27, pp. 129-147.

Leeper, E. and Zha, T. (2003) "Small Policy Interventions", Journal of Monetary Economics, vol. 50, pp. 1673-1700.

Lubik, T. and Schorfheide, F. (2004) "Testing for Indeterminacy: An application to US monetary Policy", American Economic Review, vol. 94, pp. 190-217

Marquez, C. (2004) "Inflation persistence: Facts or artifacts?", ECB Working Paper No. 371.

McConnell, M. and Perez Quiroz, G. (2001) "Output fluctuations in the US: What has changed since the early 1980s?", American Economic Review, vol. 90, pp. 1464-1476.

Mumtaz, H. and Surico, P. (2006) "Evolving International Inflation Dynamics: World and country specific factors", Bank of England, manuscript.

O'Really, G. and Whelan, K (2004), "Has the Euro are Persistence Changed over Time?", ECB Working Paper No. 335.

Pappa, E. (2004) "New-Keynesian or RBC transmission? The effects of fiscal shocks in labour markets", IGIER Working Paper No. 293.

Primiceri, G. (2005), "Time varying structural VAR and monetary policy, Review of Economic Studies, Vol. 72, pp. 821-852.

Sims, C., A. and Zha, T. (2006), "Were there regime switches in US monetary policy?", American Economic Review, vol. 96, pp. 54-81.

Stock, J. and Watson, M. (2003) "Understanding changes in Business Cycle dynamics", NBER Working Paper, No. 9859. 

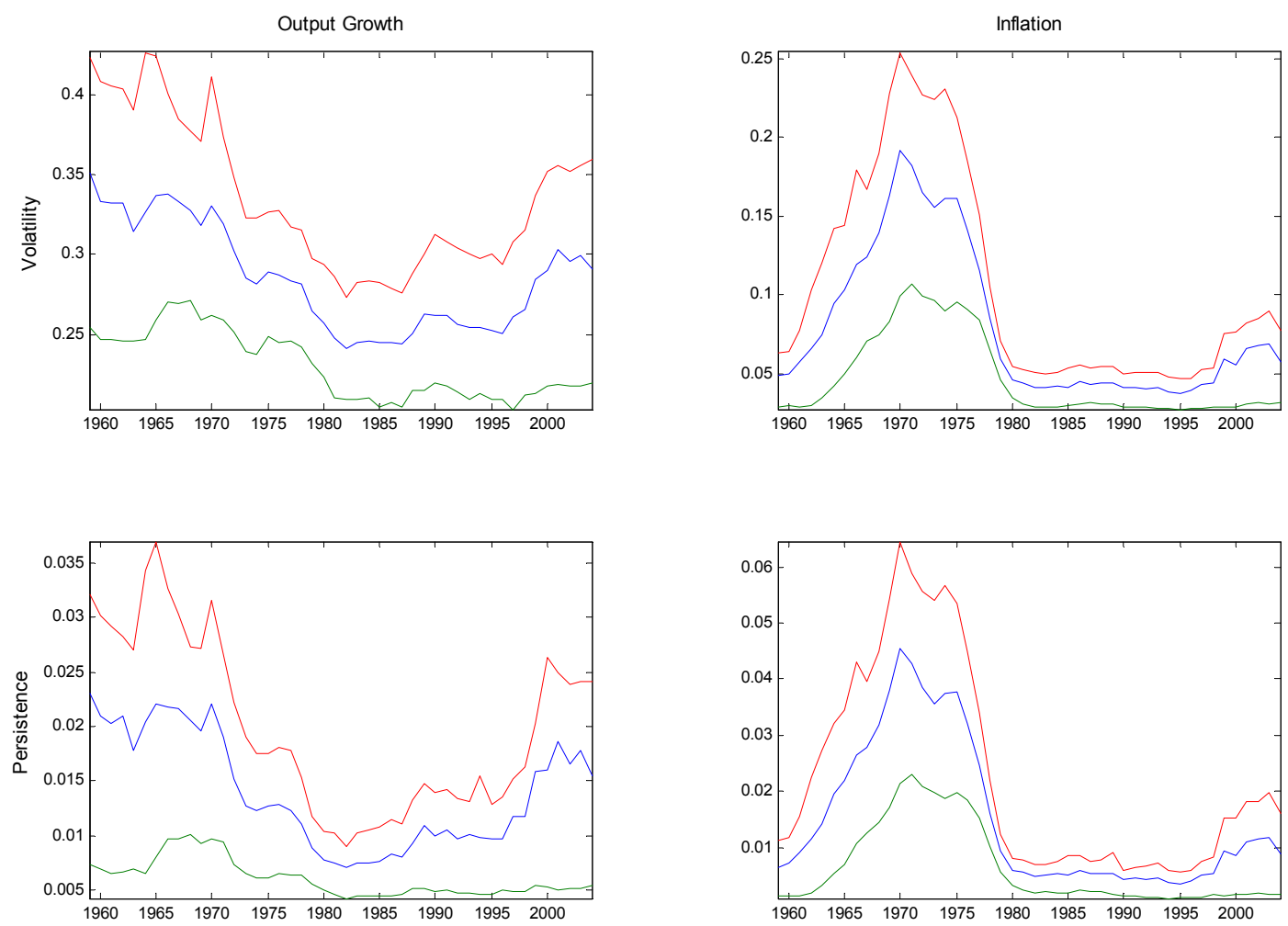

Figure 1: Persistence and Volatilities, US.
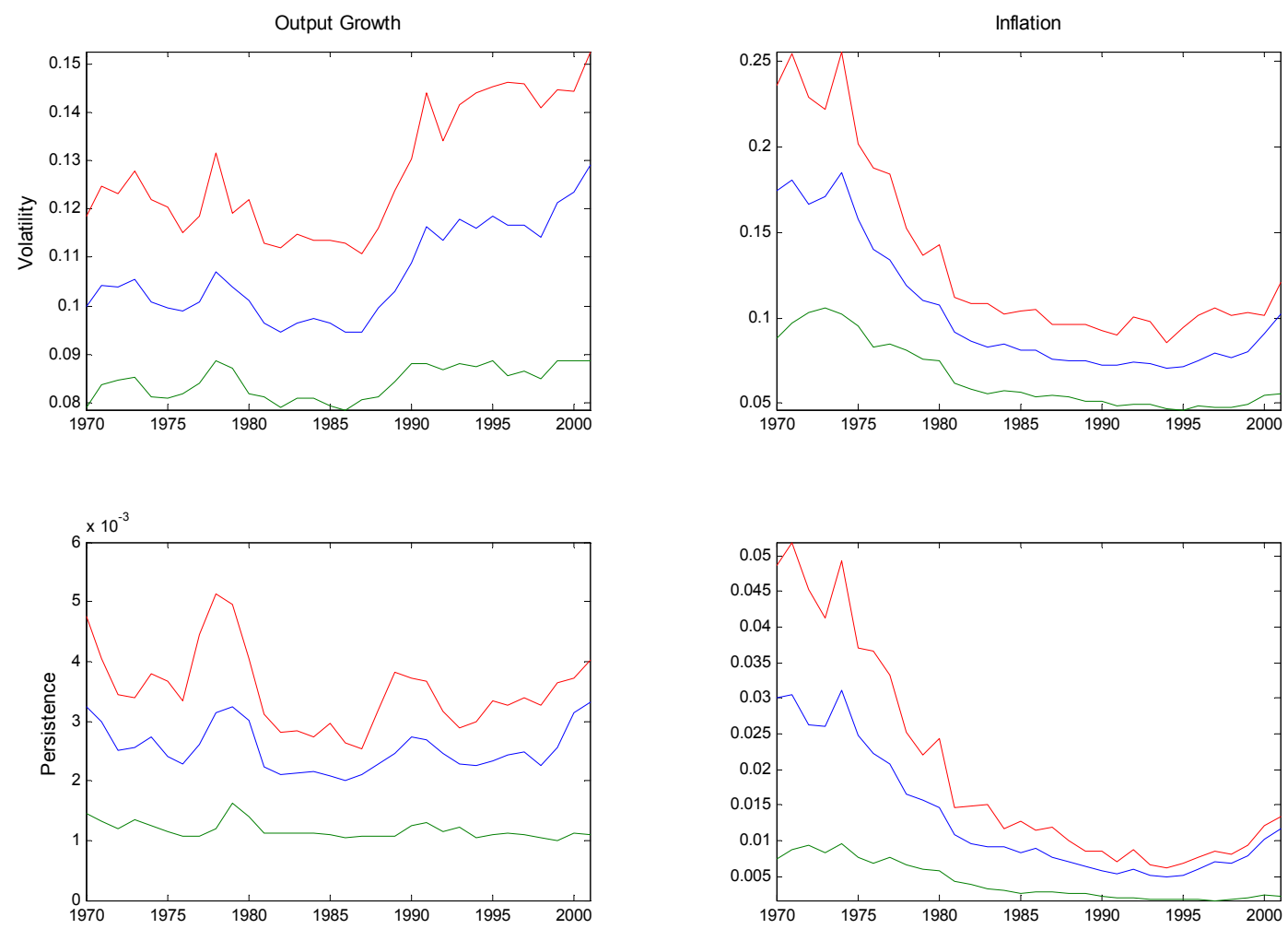

Figure 2: Persistence and Volatilities, Euro Area. 

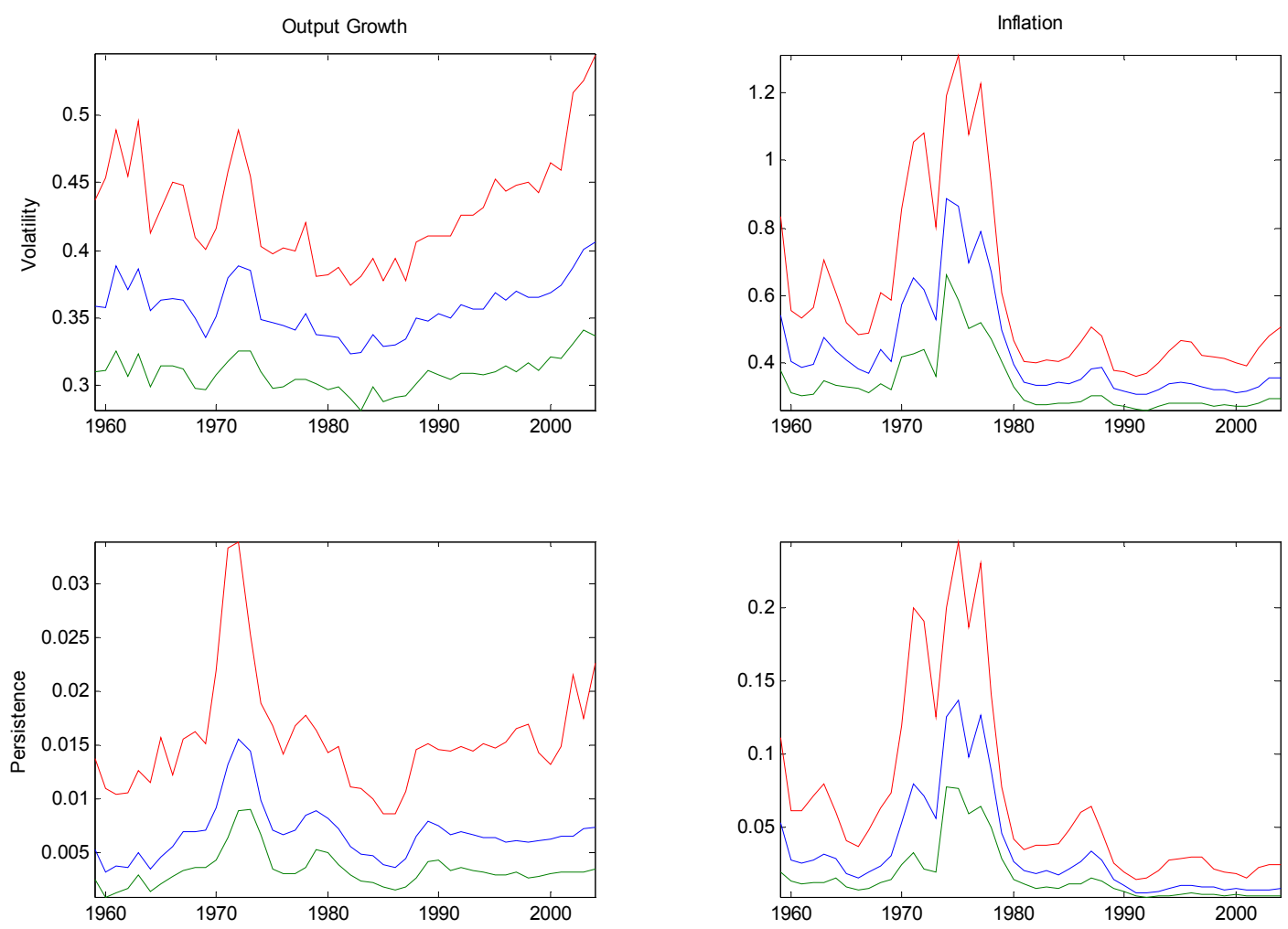

Figure 3: Persistence and Volatilities, UK. 

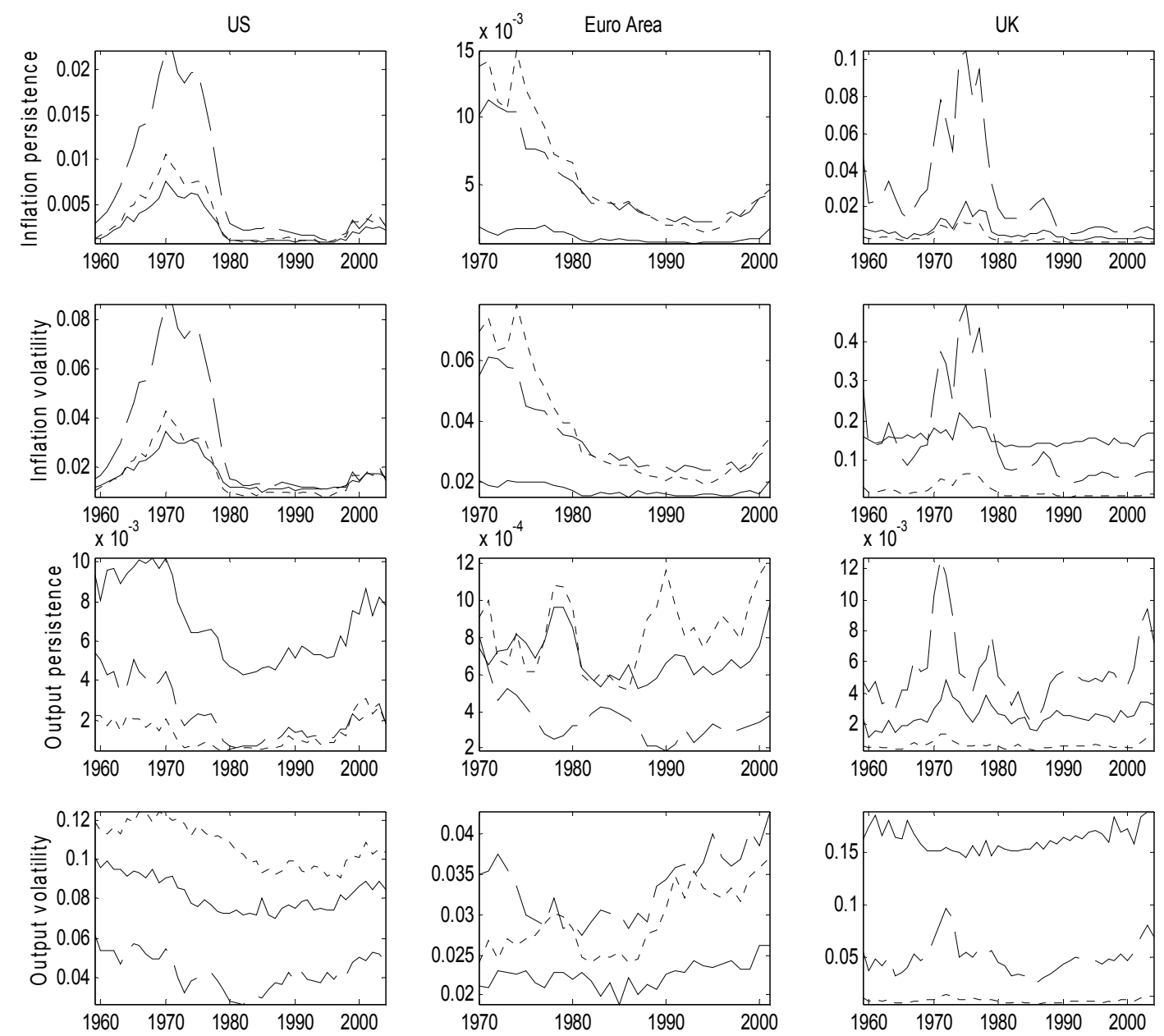

Figure 4: Sources of output growth and inflation dynamics. Solid - supply shock. Dashed - demand shock. Dotted - monetary policy shock. 

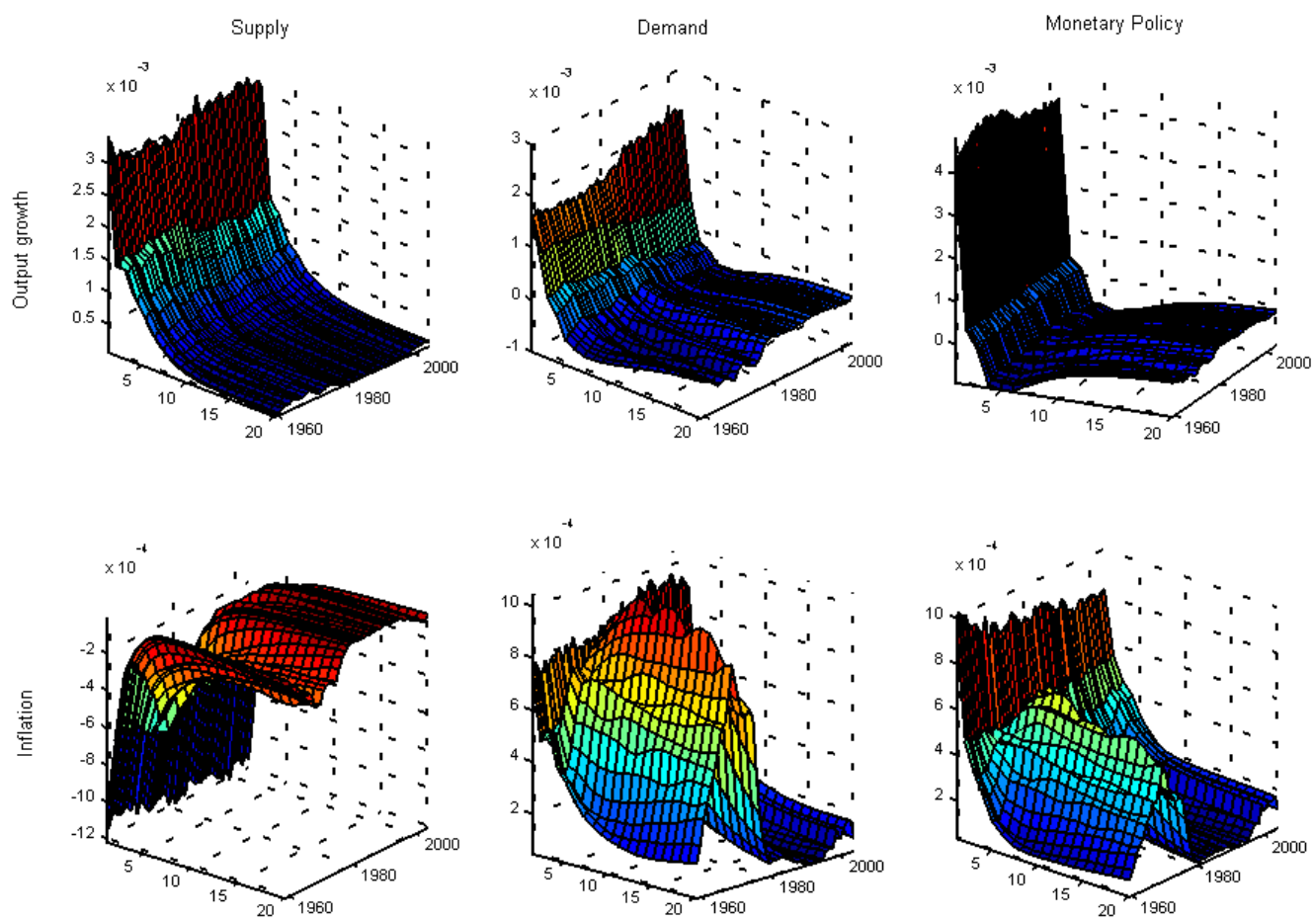

Figure 5: Responses of Output growth and Inflation, US
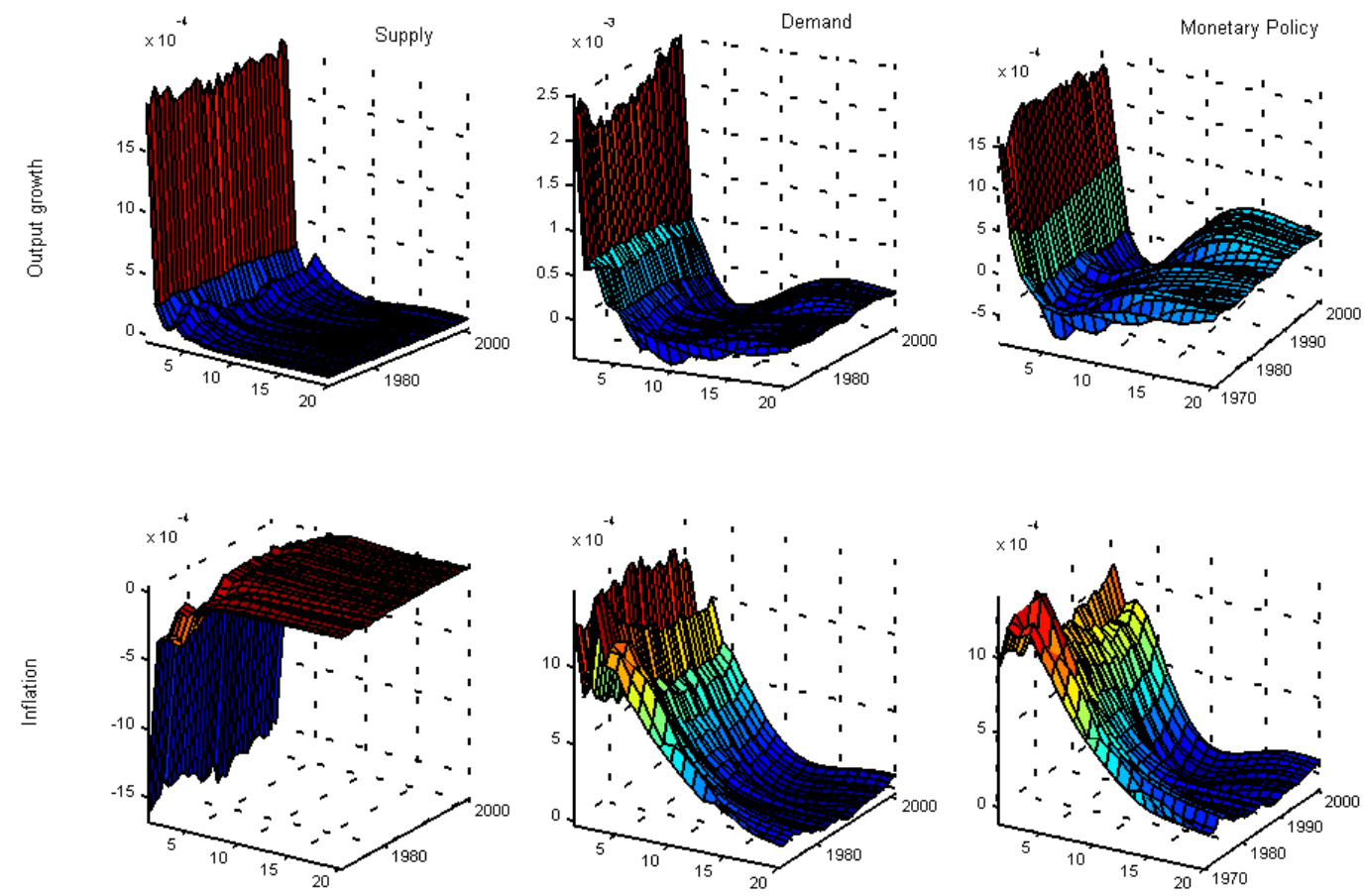

Figure 6: Responses of Output growth and Inflation, Euro Area 

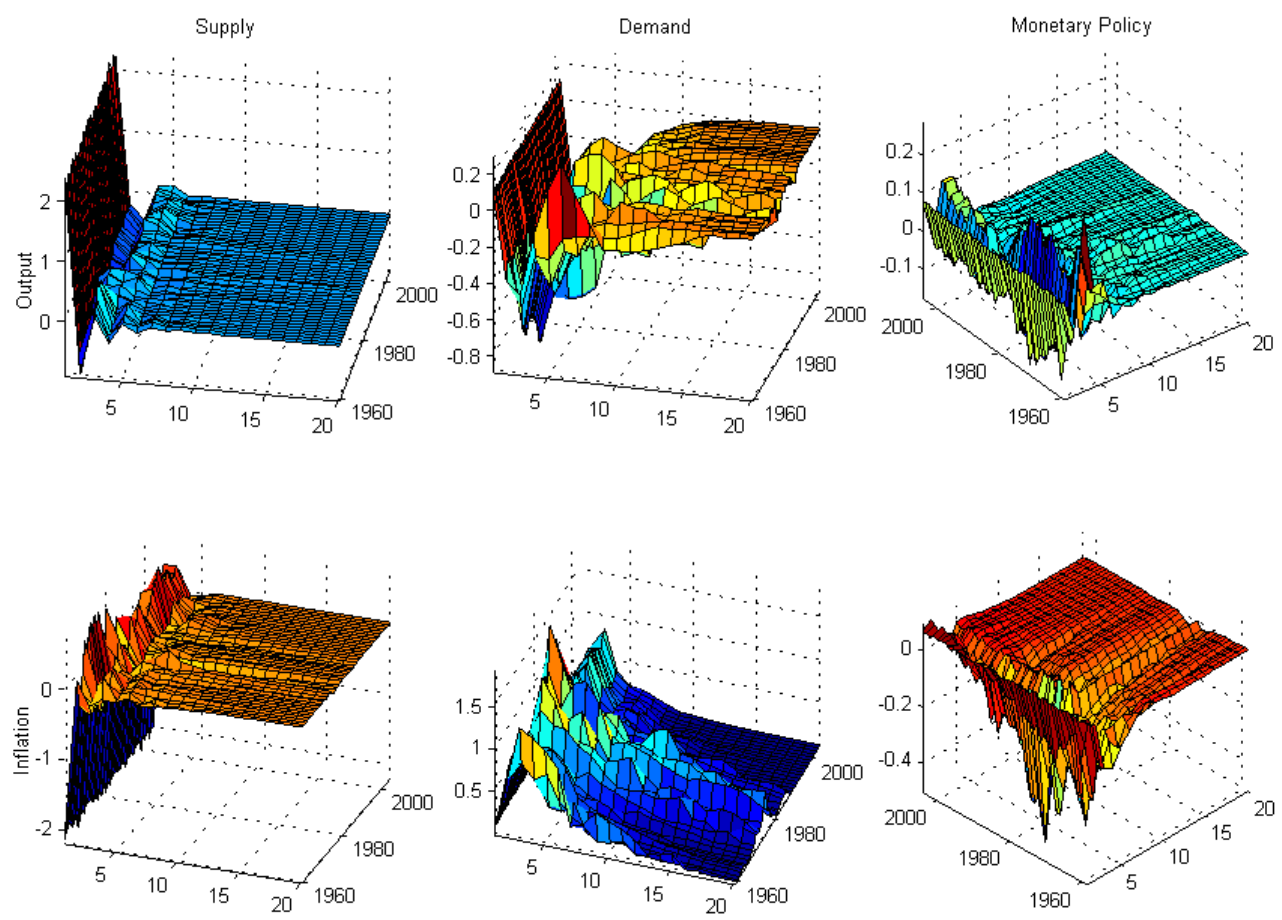

Figure 7: Responses of Output growth and Inflation, UK 

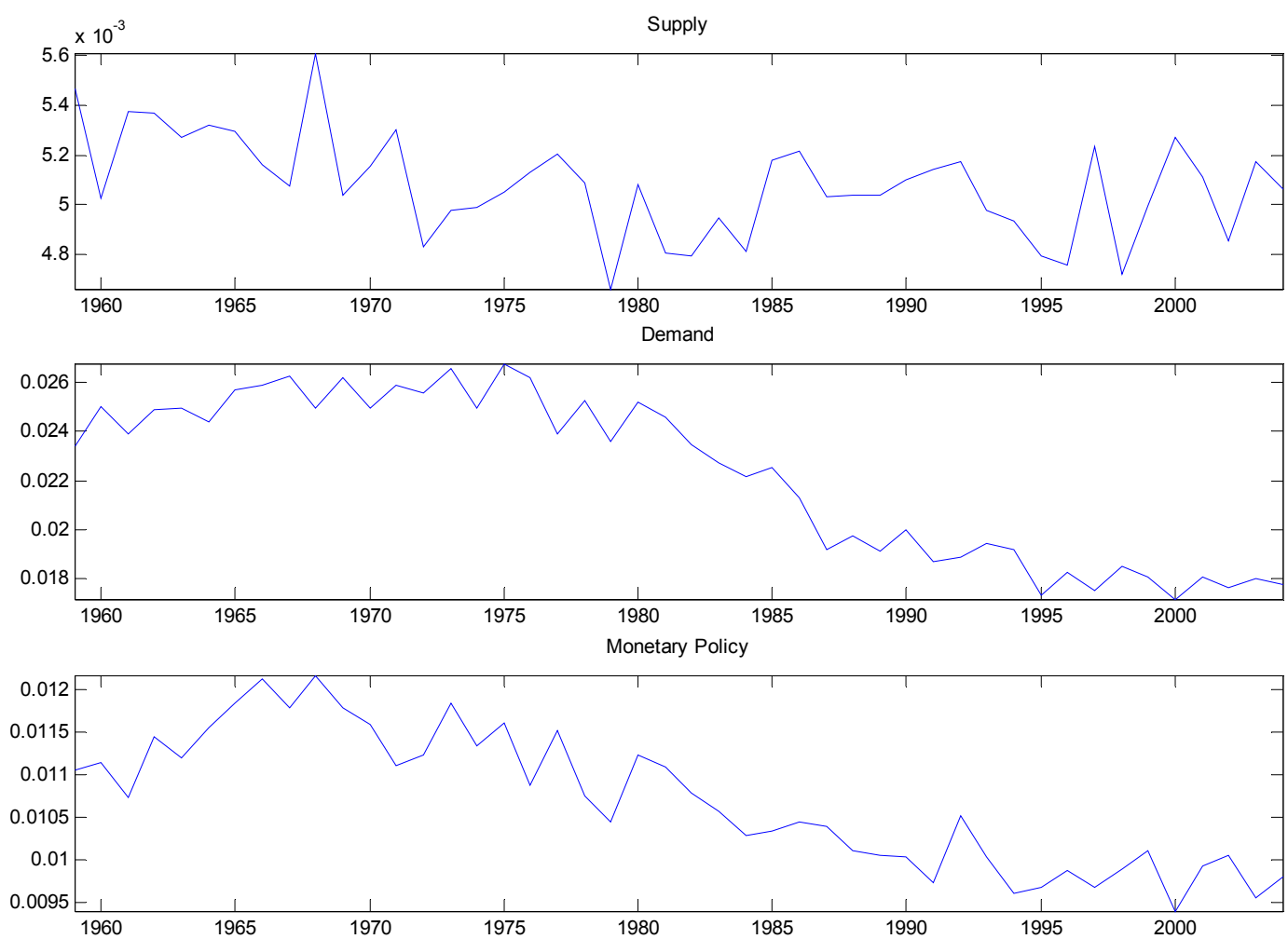

Figure 8: Posterior median of the variances of structural shocks, US
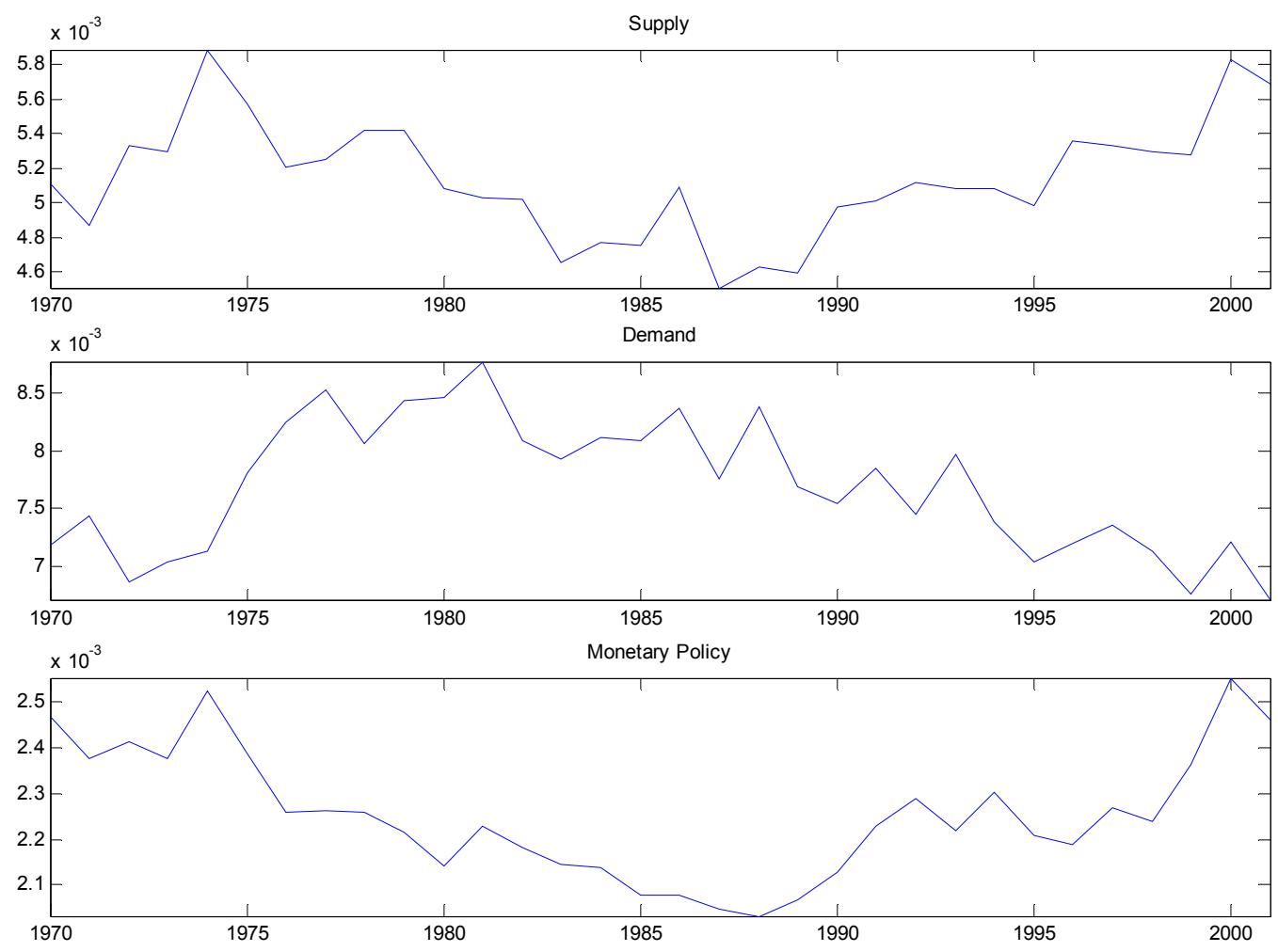

Figure 9: Posterior median of the variances of structural shocks, Euro Area 

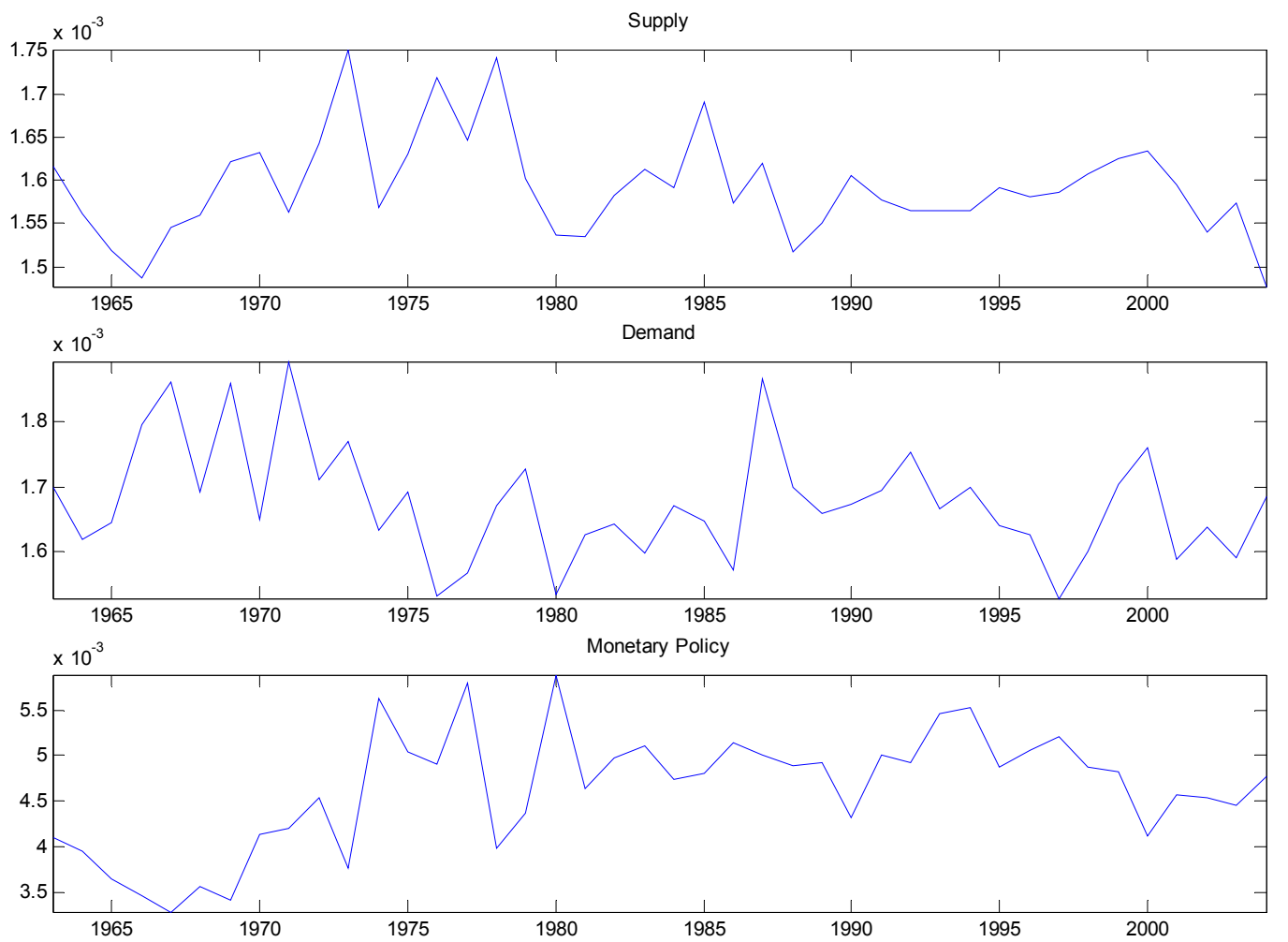

Figure 10: Posterior median of the variances of structural shocks, UK 